\title{
Affect Phobia Therapy for Mild to Moderate Alcohol Use Disorder: The Cases of "Carey," "Michelle," and "Mary"
}

\author{
My Frankl ${ }^{\text {a,b,g }}$, Peter Wennberg ${ }^{\text {d,e }}$, Lene Berggraf ${ }^{\text {f }}, \&$ Björn Philips ${ }^{\text {a,b,c }}$ \\ ${ }^{a}$ Department of Behavioral Science and Learning, Linköping University, Linköping, Sweden \\ ${ }^{\mathrm{b}}$ Stockholm Center for Dependency Disorders, Stockholm County Council, Stockholm, Sweden \\ ${ }^{\mathrm{c}}$ Competence Center for Psychotherapy, Center for Psychiatry Research, Department of Clinical Neuroscience, \\ Karolinska Institutet, Stockholm, Sweden \\ ${ }^{\mathrm{d}}$ Center for Social Research on Alcohol and Drugs, Stockholm University, Stockholm, Sweden \\ ${ }^{\mathrm{e}}$ Department of Public Health Science, Karolinska Institutet, Stockholm, Sweden \\ ${ }^{\mathrm{f}}$ Modum Bad Psychiatric Center, Research Institute, Vikersund, Norway \\ $\mathrm{g}$ Correspondence regarding this article should be sent to My Frankl, Magnus Huss-mottagningen, Beroendecentrum \\ Stockholm, Gävlegatan 22C, SE-113 30 Stockholm, Sweden \\ Correspondence \\ Email: my.frankl@sll.se \\ Acknowledgments: This study was supported by ALF funding from Stockholm County Council and Karolinska \\ Institutet. We thank Sara Frankl for her valuable contribution in the construction of checklists and figures, and Björn \\ Frankl for his essential technical support.
}

\begin{abstract}
Affect Phobia Treatment (APT) is based on an integrative theory involving the use of psychodynamic principles for understanding a client's psychological dynamics, experiential principles for engaging and working with the client's affect, and behavioral principles of exposure and response prevention for desensitizing the client to the fear of affect. APT's goal is "to help patients function better by resolving emotional conflict through reducing their avoidance of adaptive, activating emotions" (Osborn et al., 2014). APT has not yet been systematically employed and researched for patients with mild to moderate Alcohol Use Disorder (AUD) together with affect phobia. The present study was designed to begin this process by describing and comparing, both qualitatively and quantitatively, three illustrative, distinctive cases of APT in patients with AUD, assigned the names of "Carey," "Michelle," and "Mary." The focus was on exploring the process by which the different individual patients responded to the multifaceted APT therapy, and hence how the therapist had to adapt the therapy to each particular patient, as outlined in Stiles' (2009) concept of "appropriate responsiveness." Following the manual for APT, therapy included 10 weekly sessions of individual psychotherapy. This short length for a therapy like APT, a treatment which usually has no determined session length (McCullough et al., 2003), was designed to make the therapy comparable in length to other therapies for AUD, like Motivational Interviewing. During the whole study period, patients gave weekly reports of their alcohol consumption and craving. In addition, at the beginning and at the end of the study, the patients answered questionnaires measuring affect phobia and psychiatric symptoms. Role expectations and experiences of psychotherapy were also measured. All three patients completed the treatment and the
\end{abstract}


measurement period. No adverse events were reported. The patients had different trajectories of change regarding alcohol consumption, craving, and symptom change. The study showed that 10-session APT was a tolerable treatment for the patients with on-going mild-to-moderate alcohol dependence, who primarily used alcohol as a way of avoiding emotions, but that the therapy worked to different degrees and in different ways for the three patients due to their different presenting patterns of psychiatric symptoms and personality characteristics. Experience in the three cases suggests the advisability of (a) flexible treatment length in accordance to a patient's needs, and (b) complementary treatment strategies beyond APT focusing on reducing alcohol consumption per se for some patients.

Key words: Affect Focused Therapy; Short-Term Psychodynamic Psychotherapy; Affect Phobia; emotional avoidance; emotional regulation self-compassion; self-criticism; alcohol dependence; case studies; clinical case studies.

\section{CASE CONTEXT AND METHOD}

\section{Aim of the Study and Rationale for Selecting the Patients}

Alcohol use disorder (AUD) is one of society's most serious problems, causing great suffering for both adults and children. Alcohol misuse is related to accidents and illnesses, and it not only harms the individual but also incurs great expenses for society. The etiology and development of AUD is complex and diverse. For a subgroup of individuals, avoidance of emotional states is thought to play an important role in increased alcohol consumption and the development of AUD (Khantzian, 1997, 2012). In this light, the present study is driven by an interest in investigating whether Affect Phobia Therapy, an integrative therapy including psychodynamic, experiential, and behavioral principles, is feasible and effective as a first-line treatment for patients diagnosed with mild-to-moderate AUD and difficulties in affective avoidance and emotion regulation.

The duration of therapy was set to 10 sessions for all patients. The decision on treatment length was based on a theoretically constructed mini-format for short-term psychodynamic treatment. The goal was to offer the shortest possible first-line treatment for patients with problematic alcohol consumption. The advantage of a short treatment is that for this patient population, the treatment can be compared to other first-line alcohol treatments such as Motivational Interviewing (MI; Miller \& Rollnick, 2002) and Relapse Prevention (RP; Marlatt \& Donovan, 2005). The disadvantage is that in comparison with other studies on short-term psychodynamic treatments, the treatment length is short.

Patients interested in receiving short-term psychological treatment were recruited to this small-N study. Female patients were chosen to keep the small sample as homogeneous as possible. Another aspect of the case context — not discussed in this case study article — was that the cases were part of a multiple-baseline design. For more details on the design, the interested reader should see the dissertation of the first author (Frankl, 2017). The focus of this article is on systematically describing and comparing, both qualitatively and quantitatively, three illustrative, distinctive cases of Affect Phobia treatment in patients with AUD. See Fishman, Messer, 
Edwards and Dattilio, (2017) for a description of analyzing systematic, mixed-methods case studies within the context of quantitatively-oriented group research.

\section{The Clinical Setting in Which the Treatments Took Place}

The study took place at the Stockholm Center for Dependency Disorders, a large publicsector addiction clinic that provides specialized care for substance use disorders for the inhabitants of most of Stockholm County, Sweden. The clinic is a public treatment facility. The patient fee for psychotherapy is $\$ 12$ per session and the yearly cap for accumulated outpatient health care is $\$ 140$, after which patients receive treatment free of charge. I conducted all three therapies at my workplace, a psychological outpatient clinic at Karolinska University Hospital in Stockholm. The patients were recruited from two other outpatient units within the Center for Dependency Disorders, where they continued to receive their medical care. At the time of the therapy, I had been trained in both traditional, short-term psychodynamic psychotherapy and in Affect Phobia Therapy (APT), and I was experienced in addiction care. All the therapy sessions were recorded on video and shown in weekly consultations with an experienced APT clinical supervisor to ensure adherence to the APT manual, and to provide clinical guidance.

\section{Procedure}

Written information about the project was sent out to psychiatrists at two outpatient units within the Stockholm Center for Dependency Disorders, where patients suitable for the study participation were treated. One clinic offers care for women diagnosed with alcohol use disorder (AUD), who have underage children. The other clinic targets patients with mild-to-moderate alcohol use disorder with no major impairment in social functioning. The two clinics were chosen since the aim was to select female patients with mild-to-moderate AUD, no other drug abuse, and a stable social situation. The information stated the inclusion/exclusion criteria for participating in the project. The first three referred patients who agreed to participate were recruited. When referrals were made, the therapist met the patient to give information about the study and the therapy method and to ensure that the inclusion criteria were met. Inclusions were made until the study sample was completed. One patient first agreed to participate but then changed her mind and thus the next patient in line was included. Inclusion criteria in the study were: (a) being a woman in the age range of 18 to 65 who had signed informed consent for participation in the study; (b) having an address in Stockholm County where the patient could be reached; (c) having a diagnosis of AUD in accordance with DSM-IV guidelines; (d) having consumed alcohol on at least five days during the last 35 days; (e) having not consumed alcohol for the last seven days (to reduce the risk for cognitive and somatic complications that might hinder psychotherapy); and (f) being screened positively for affect phobia ( $<70$ points, which is in the clinical range on the reversed-scored Affect Phobia Test (Frankl et al., 2016).

Exclusion criteria were: (a) having one or more severe Axis I disorders indicating a need for intensive psychiatric treatment (such as a psychotic disorder, a severe bipolar disorder, a severe major depression, an autism spectrum disorder, or marked cognitive dysfunction due to mental retardation, (b) currently using substances other than alcohol [nicotine and caffeine excluded]); (c) having a severe Axis II disorder (i.e., paranoid, schizotypal, antisocial, and/or borderline personality disorder); (d) having dementia, organic brain lesion, severe somatic 
illness; (e) being unable to communicate in Swedish without an interpreter; and/or (e) being in ongoing psychotherapy outside the project.

At inclusion, data on the patient's alcohol consumption for the last three months were collected. Inclusion measures included the Time Line Follow Back (TLFB); the Penn Alcohol Craving Scale (PACS); the Outcome Questionnaire-45 (OQ-45); the Psychotherapy Expectations and Experiences Scale-short version (PEX-S), the Affect Phobia Test; and a laboratory analysis of the patient's blood for Carbohydrate-Deficient Transferrin (CDT). (More details about the measures are provided below.)

The treatment consisted of three sequential phases:

- $\quad$ Phase $\mathrm{A}^{1}$, baseline, consisted of a baseline period where the patient met with the clinic's nurse, who asked questions about the previous week's alcohol consumption and administered a self-report questionnaire on craving (TLFB and PACS). This period continued four, six, or eight weeks according to randomization (in conjunction with the separate, multiple-baseline research study mentioned above) as follows for the three patients: Carey, four weeks; Michelle, eight weeks; and Mary, six weeks.

- Phase B, therapy, consisted of individual Affect Phobia Therapy once a week for 10 weeks. All sessions were recorded on videotape to ensure that the treatment was conducted according to the APT manual. The first therapy session was 90 minutes long to facilitate initiation of the accelerated therapy, which was shorter than the usual APT therapy, and the following sessions were 45-50 minutes long. Before every treatment session, the patient met with the nurse who collected data on craving and alcohol consumption (PACS and TLFB).

- $\quad$ Phase $\mathrm{A}^{2}$, follow-up, began after therapy ended and consisted of a four-week period for all three patients where the nurse collected data about the previous week's alcohol consumption and administered a self-report questionnaire on craving (TLFB and PACS). Data was collected by phone or by mail.

\section{Measures}

The primary outcome measure was Heavy Episodic Drinking (HED; $>45$ gram alcohol/day for women), and the secondary outcome measure was Consumption (CONS), both measured with the Time Line Follow Back (TLFB; Sobell \& Sobell, 1992; Wennberg \& Bohman, 1998). The TLFB is used for collecting the patient's retrospective estimation of his or her use of alcohol. The measure is administered in an interview using a calendar going back day-by-day. TLFB was then administered every week through the whole study. TLFB has been shown to have adequate reliability (Wennberg \& Bohman, 1998).

Craving was measured with the Penn Alcohol Craving Scale (PACS; (Flannery, Volpicelli, \& Pettinati, 1999), a self-report questionnaire consisting of five items on one scale with questions about the frequency, intensity, and duration of cravings together with the ability to resist drinking; and a question on the overall craving for the previous week. Answers are given on a seven-point Likert scale and scored from 1 ("Never) to 7 ("Almost always"), with a score 
range of 0-34). Flannery and colleagues demonstrated adequate reliability of the PACS, with an internal consistency os $\alpha=.92$. PACS was administered once a week through the whole study.

Phobia of affects was measured at inclusion and at follow-up with the Affect Phobia Test (Frankl et al., 2016), a self-report questionnaire. The Affect Phobia Test consists of 20 items distributed over seven dimensions. Answers are given on a five-point Likert scale and are scored from 1 ("Not at all") to 5 ("Very much"), with a score range of 20 to 100 . The seven dimensions are: Anger-Assertion, Sadness-Grief, Attachment-Closeness/Tenderness, Sexual Feelings, Positive Feelings Towards the Self, Interest-Excitement, and Enjoyment-Joy. The psychometric properties of the Swedish version of the Affect Phobia Test show satisfactory reliability in terms of internal consistency (for a clinical sample, $\alpha=0.88$; for a sample of university students, $\alpha=$ $0.84)$; and in terms of test-retest reliability $\left(r_{\mathrm{xx}}=0.70\right.$ for the total scale).

Outcome Questionnaire-45 (OQ-45; Lambert et al., 1996) was measured at inclusion and follow-up. The self-report measure consists of 45 items distributed over three central outcome domains of symptom distress, interpersonal problems, and social role functioning. Answers are given on a five-point Likert scale and scored from 1 ("Never") to 5 ("Almost Always"), with a total score ranging from 45 to 225). The Swedish translation has shown good psychometric properties when tried out with a substance abuse sample, except for a somewhat low internal consistency on the social role subscale $(\alpha=.63)$. Internal consistency for the total score was $\alpha=$ .95 (Wennberg, Philips, \& de Jong, 2010).

Psychotherapy Expectations and Experiences Scale-short version (PEX-S; (Clinton \& Sandell, 2003; Frankl, Philips, \& Wennberg, 2014) was used for assessing patients' treatment expectations at pre-treatment, as well as their experiences of therapy, measured at follow-up. PEX-S is a 25-item instrument distributed on five subscales. The five subscales are: external orientation, internal orientation, catharsis, support, and defensiveness. Answers are given on a six-point Likert scale and scored from 1 ("disagree completely") to 6 ("agree completely"). The total score ranges from 25-150). All subscales in the PEX-S have shown satisfactory internal consistency, with Cronbach's alpha ranging between .79 and .84 (Frankl et al., 2014).

Blood Samples were collected at the study site at inclusion and at a dependency care unit or primary care unit at the end of the follow-up period. The laboratory analysis of blood used was carbohydrate-deficient transferrin (Sharpe, 2001), which reflects the average alcohol consumption during a period of one to four weeks prior to testing. A reference interval $>2.0 \%$ indicates heavy drinking.

\section{Confidentiality}

Patients received verbal and written information about the background, purpose, and procedures of the study; about the reason the patient had been asked to participate in the study; and about possible discomforts and benefits associated with participation. Patients were also informed that participation was voluntary and could be discontinued at any time point with absolutely no effect on their care at the clinic. Patients were informed that their confidentiality would be guaranteed if the study results were published since personal data would be deidentified. In this case study, personal information that could be revealing in the description of 
the therapy processes has been omitted and the patients' names are fictitious. The three patients gave their written consent for participation in the study and for the data to be used in evaluation and possible publication. The study was conducted with the permission from the Regional Ethics Committee in Stockholm (Study Number: 2011/144-31).

\section{THE CLIENTS}

All three of the patients were born in Sweden. All had experienced the onset of alcohol use disorder after the age of 30 . They had contacted addiction care services on their own initiative within the year prior to the onset of the study and had never before received treatment for alcohol problems. Finally, none of the patients had any comorbid psychiatric diagnosis.

At the beginning of therapy, Carey was 60 years old. An only child, she had fond memories of her parents. After two failed marriages, she had been living with her third husband for 10 years in a generally stable relationship. She had two grown-up sons and was very attached to her grandchildren. Her husband was the only person who knew about her alcohol dependence.

Michelle was 44 years old. She was an only child, remembering her childhood as one of insecurity and loneliness. Michelle had a university degree but had had difficulty finding a position in her line of work. Michelle was living with a partner and their nine-year-old child. The relationship between Michelle and her partner had gone down hill over the years, but she was closely bonded to her son. She kept her drinking problem a secret from family and friends.

Mary was 46 years old. She was the oldest of three children and described her upbringing as secure but with little room for emotional expression. She lived with her husband and their two teenage children. Mary had a university degree in fine arts and worked in her own private company. Mary kept her drinking problems a secret from her friends and extended family.

\section{GUIDING CONCEPTION WITH RESEARCH AND CLINICAL EXPERIENCE SUPPORT}

\section{Alcohol Use Disorder (AUD)}

The progress and cause of AUD is multifaceted, with hereditary, personal, and environmental aspects impacting its development. Several attempts have been made to develop an empirically grounded typology of alcohol dependence (Leggio, Kenna, Fenton, Bonenfant, \& Swift, 2009), but consistent results of their relevance have not yet been produced (Babor \& Caetano, 2006). All typologies have demonstrated an ability to identify relatively homogenous groups, but examination of their diagnostic validity and matching to treatment has yet to be carried out (Hesselbrock \& Hesselbrock, 2006). The most well-known are two-type models, including the distinctions between Type I and Type II (Cloninger, 1981), and Type A and Type B (Babor, 1992). These two models are quite similar. Type I/A is characterized by later onset, less severe symptoms of alcohol dependence, less severe psychotherapy, and drinking with the desire to avoid harm. Type II/B is characterized by more severe symptoms of alcohol dependence, more severe psychopathology, more familial alcoholism, and drinking for pleasure. However, two-group solution typologies do not seem to fully capture clinical and general samples (Hesselbrock \& Hesselbrock, 2006). Two four-type cluster solutions with similar 
subtyping have emerged in the analysis of two different samples (Windle \& Scheidt, 2004; Hesselbrock \& Hesselbrock, 2006). In these, depressive and anxiety symptoms are highlighted.

The self-medication hypothesis of substance abuse suggests that the use of alcohol and drugs are means to relieve painful affects, control affects when they are confusing, or to activate affects when they are absent as well as to cope with difficulties regarding self-esteem, relationships, and self-care (Khantzian, 1997, 2012). The model builds on supposition that addiction is a dysfunctional attempt to regulate affects and to compensate for problems of the self. As such, substance use disorder becomes a self-regulation disorder.

Regarding the self-medication hypothesis, past research on drinking has conceptualized at least two general motives for drinking: first, drinking to cope by changing one's emotional experience and avoiding unpleasant emotional states; and second, drinking to enhance one's experience by striving to increase positive emotions. Both of these internally driven motives have been associated with high alcohol consumption and the risk of developing problematic drinking behavior (Cooper, Frone, Russell, \& Mudar, 1995; Kuntsche, Knibbe, Gmel, \& Engels, 2005). Also in line with the self-medication hypothesis, strong associations with anxiety disorder or depressive disorder have been found in individuals who use alcohol as a way of coping with a multitude of emotional experiences (Stapinski et al., 2016); and high alcohol intake has been associated with emotion regulation difficulties (Aurora \& Klanecky, 2016; Dvorak et al., 2014). Thus, past research indicates that emotions play a central role in the development of alcoholrelated problems. The self-medication hypothesis might be particularly relevant for patients with Type 1/A AUD, that is, later onset, less severe symptoms of alcohol dependence, less severe psychopathology, and drinking with the desire to avoid harm; and also with other subtypes that highlight depressed and anxious subtypes of alcohol dependence.

Based on the extensive research review of treatments for alcohol and drug abuse by the Swedish Council on Health Technology Assessment in Health Care (Berglund et al., 2003), a number of psychological treatments for alcohol dependence have shown enough evidence to be recommended for use, such as Response Prevention (Marlatt \& Donovan, 2005) and Motivational Interviewing I (Miller \& Rollnick, 2002). The list of psychological treatments with empirical support also includes psychodynamic therapy and interactional psychotherapy, a therapy which targets immediate feelings and explores patients' relationships (Brown \& Yalom, 1977); and some analyses have indicated that no one method shows better effects compared with any other (Berglund et al., 2003). Some differences in techniques, such as the use of an empathic, engaging approach, have been shown to improve outcomes marginally (Miller \& Rollnick, 2002).

However, understanding of the major efficacious therapeutic mechanisms or principles for treatment of alcohol use disorder is still unclear. Berglund and colleagues show that even evidence-based combinations of pharmacological and psychological treatments still leave a large proportion of patients without significant improvement. The patient group targeted in our study belongs to Type I/A. Previous studies that have provided empirical support for psychological treatments focusing on insight and emotional experiencing have mainly targeted patients with Type I/A alcohol dependence, that is, trials including psychodynamic therapy (Ojehagen, Berglund, Andersson, Nilsson, \& Skjaerris, 1993; Sandahl, Herlitz, \& Ahlin, 1998) and interactional therapy, a group therapy developed by Irwin Yalom and adapted to alcohol 
dependence (Brown \& Yalom, 1977). Interactional therapy has been tested in several randomized controlled studies with positive results, although there are no significant differences in comparison to cognitive-behavioral treatment (Cooney, Kadden, Litt, \& Getter, 1991; Kadden, Cooney, Getter, \& Litt, 1989; Kadden, Litt, Cooney, Kabela, \& Getter, 2001a; Litt, Babor, DelBoca, Kadden, \& Cooney, 1992).

\section{Affect Phobia Therapy (APT)}

Developed by Leigh McCullough (McCullough et al., 2003; McCullough \& Vaillant, 1997), APT is an integrative therapy with psychodynamic, experiential, and behavioral components. It is designed "to help patients function better by resolving emotional conflict through reducing their avoidance of adaptive, activating emotions" (Osborn et al., 2014); and it has established a formal, international training program ( http://affectphobiatherapy.com/). APT's core consists of a short-term, psychodynamic theoretical base, with a primary focus on the dysfunctional inhibition versus the adaptive regulation of affects, as well as a focus on the patient's longing for nurturing and protective attachment, the deprivation of which can give rise to grief and anger. The therapy is characterized by high therapist activity, in which the therapist clarifies and affirms the patient's experience rather than confronting the patients' defenses and maladaptive behavior. Another important aspect of APT is psychodynamic conflict theory, that is, the view that a hidden, "dangerous" impulse or emotion can lead to anxiety, which in turn leads to a defense against the impulse/emotion, intended to reduce the anxiety

In addition to psychodynamic theory, clinical aspects of affect theory and attachment theory are integrated into APT, embracing the ideas that (a) affects can both motivate healthy, adaptive behavior and lead to unhealthy maladaptive behavior, but also (b) that emotional closeness to others and positive feelings toward the self are clinically relevant affect complexes. Tomkins (1962) assumed that all human beings are born with a set of basal affects that will function as primary motivators of behavior since affects amplify whatever experience they are associated with. Each affect provides a potential for actions and communication with the environment by body language and facial expressions (Aviezer, Trope, \& Todorov, 2012; Ekman, 1992). Emotions are experienced as positive, negative, or neutral but are nevertheless adaptive and essential to attend to since they alert us to matters of importance to our survival as well as to our social and psychological wellbeing. Inability in accessing and processing emotional information of any kind thus deters an individual from engaging in one of evolution's most meaningful motivational systems.

The basic concepts of activating and inhibitory affects provide a framework for understanding problem behavior in APT. Adaptive activating affects (positive feelings toward the self, grief, anger/self-assertion, pride, closeness, healthy fear, and sexual feelings) motivate the person to approach various actions, whereas inhibitory affects (shame, guilt, pain, disgust, and anxiety) function to inhibit various actions (McCullough Vaillant, 1997). These two systems need to be in balance. For example, for healthy functioning a person should be able to fully experience a grief response without too much inhibitory pain; to assert his or her self with only a moderate amount of anxiety; and to feel guilt in an appropriate proportion when doing wrong. In the model, the expression of anger/self-assertion is considered adaptive in the sense that it enables the person to establish healthy limits for acceptable behaviors from others. However, when individuals throughout life are hindered from feeling and expressing activating affects, 
these will instead become linked with anxiety, shame, and emotional pain, and hence be defended against.

The foundation of APT has been provided by Malan's (1995) two triangles, as below:

\begin{tabular}{|c|c|}
\hline Defense Anxiety & Therapist \\
Affect/Impulse & Parrent Persons \\
Malan's Triangle of Conflict & $\underline{\text { Malan's Triangle of Persons }}$ \\
\hline
\end{tabular}

The concept of affect phobia refers to the triangle of conflict, in which a certain activating, adaptive affect triggers an inhibiting affect (anxiety, shame, emotional pain), which pushes the individual to a defensive or avoiding behavior in order to get rid of the painful affects. The defensive behavior can also be an expression of an affect-for example, anger.

The triangle of persons shows how the these reaction patterns were learned with past persons, continue in present relationships, and can become visible together with the therapist where a relearning process can begin. Extensive use of defensive/avoidant strategies comes at considerable cost (e.g., lack of intimacy, loneliness, somatic problems, energy loss, inflexible behavior patterns, and substance/alcohol abuse), and these strategies often lead to what we refer to as psychiatric symptoms or problematic behaviors (McCullough et al., 2003).

In APT the focus is on recognizing, experiencing, understanding, and finally expressing affects adaptively. Patients are gradually exposed (see below) to feelings that have been avoided, and patients are trained to better regulate feelings that are too dominant in their lives. The goal of treatment is that the patient will more frequently be guided by their feelings toward a new adaptive behavior repertoire. APT recognizes that positive feelings toward oneself can often be feelings that patients normally avoid. Therefore, the goal of APT treatment-shown in the triangle below - is to reduce excessive self-criticism, e.g., as expressed in defensiveness and in anxiety, so as to enhance positive feelings for the self. The concept of the triangles as carried out in working with clients in developing case formulations is presented in Table 1 below. In the present case studies, this form was translated into Swedish.

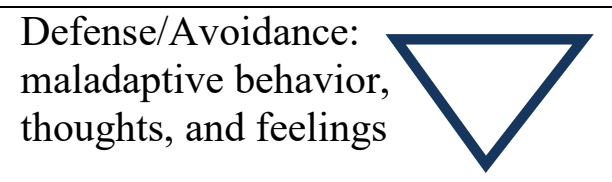

Anxiety/Inhibiting Affects:

shame, guilt, and fear

Impulse/Activating Adaptive Affect:

positive feeling toward the self,

positive feelings towards others/closeness

\section{$\underline{\text { Triangle of Conflict in APT }}$}


Behavioral principles of exposure and response prevention (Abramowitz, Deacon, \& Whiteside, 2010) are used to desensitize the fear of affect. To help patients experience affects, specific emotional memories from the past as well as present relational episodes are elicited in therapy. The goal is to expose the patient to adaptive affects. Specific interventions are used to encourage the experience of affect. Patients are aided in verbally labeling emotions as well as describing the physiological sensation of the emotion. To further promote the experience of affect and to train patients to avoid impulsive acting out, the therapist will guide the patient through scenes in fantasy form, having the patient imagine what their action (the adaptive expression of affect) might be. These scenes will then be repeated until desensitization is accomplished.

The next step toward the primary goal of therapy (i.e., to express wants and needs in a regulated adaptive manner) is to express affect and enhance receptivity to others' affects. To access and practice the expression of affect, the therapist and patient in collaboration can choose between a wide range of experiential techniques, such as role-playing and the two-chair technique (Greenberg, 1984). An interpersonal situation that represents the core dynamic conflict is thus dramatized in therapy, which will expose the patient to the feared interaction and provide training in responding in accordance with what the patient adaptively wants and needs (McCullough et al., 2003; McCullough Vaillant, 1997). The two-chair technique and switching chairs have the advantage of enabling the patient to enact both parts of an internal dilemma (conflicting feelings toward the self) or relating to an important person in the patient's life. The purpose of using experiential methods is to deepen feelings, a goal that is difficult to reach by simply talking about them (Greenberg, 1984).

APT has been tested empirically in a few studies and been shown to be as effective as other relevant bona fide therapies. In one study patients with personality disorders were randomized to APT, brief adaptive psychotherapy, or a waiting list. The results showed improvements in psychiatric symptoms, social adjustment and target complaints for the two therapy conditions compared to no treatment, but no difference between the two treatments. The results were sustained after 18 months (Winston et al., 1994). In another randomized controlled study (Svartberg, Stiles, \& Seltzer, 2004) comparing APT with cognitive behavior therapy for patients with cluster $\mathrm{C}$ personality disorders, patients showed statistically significant improvements in symptom distress, interpersonal functioning, and personality pathology after treatment, regardless of treatment modality. Symptom change as well as better interpersonal functioning continued to occur after treatment (measured up to two years) and was particularly strong in reaching significance for patients in APT (Svartberg, Stiles, \& Seltzer, 2004).

Several process analyses have been conducted on the cases in the Svartberg et al. (2004) study. These show that experiencing activating affects correlated with self-compassion and a more realistic sense of self and others; and that focusing on affects proved to be helpful for the alliance and outcome in the Affect Phobia Treatment group (Berggraf, Ulvenes, Hoffart, McCullough, \& Wampold, 2014; Ulvenes et al., 2012). An increase in self-compassion was also found to significantly reduce psychiatric symptoms, interpersonal problems, and personality pathology (Schanche, Stiles, McCullough, Svartberg, \& Nielsen, 2011). Thus, studies show that APT is beneficial for patients with personality disorders in a manner that is consistent with APT theory. For more information about APT see http://www.affectphobiatherapy.com. 
As yet, APT has not been tested for alcohol problems, but the method has some similarity to interactional therapy (Brown \& Yalom, 1977), which, as mentioned above, targets immediate feelings and explores patients' relationships. Since previous research has found that emotion regulation difficulties, avoidance of negative emotions, and enhancement of positive emotions can lead to problematic drinking behavior, we wanted to explore whether a psychotherapy aimed at enhancing adaptive affective functioning and self-soothing could help in reducing alcohol consumption and decrease comorbid psychiatric symptomatology. Problematic alcohol consumption is here understood as a maladaptive coping strategy, which operates in the same way as a defense. In sum, AFT assumes that a person drinks to suppress negative emotion and to enhance positive emotion; and Affect Phobia Therapy aims at finding more adaptive ways of being in contact with negative, inhibitory affects and positive, activating affects.

\section{A. CAREY'S ASSESSMENT: PRESENTING PROBLEMS, GOALS, STRENGTHS AND HISTORY}

Carey was 60 years old, born in Sweden. She was an only child and cherished her parents who had given her lots of love and support. Her parents were now dead and Carey felt guilt because of the worry she caused them in reaction to the problems in her second marriage. Early in life she had formed and sustained lasting romantic relationships but had longed for more energy and adventure. She had ended her first marriage and continued into a destructive second marriage.

Carey had a high school degree and had worked in a company performing administrative duties, from which she now had retired. Carey was living with her third husband, whom she had married 10 years previously. The marriage was stable and they both gave each other support, but Carey could rage at her partner, especially when she was drunk, and devalued him privately.

She had two grown up sons, and grandchildren whom she valued immensely and tried to spend time with as often as she could. Carey had deep feelings of guilt toward her children related to their childhood experiences in her second marriage.

She suffered from social anxiety and a prevailing feeling of worthlessness. Carey had told no one about her drinking problem and never before had sought help. Her husband was the only person that knew of her alcohol dependence. Her goals in therapy were to become more natural and more true to herself in relation to the people she cared for, and also to be open and loving toward herself and others.

\section{A. CAREY'S CASE FORMULATION AND TREATMENT PLAN}

\section{Formulation}

Carey had a safe and loving upbringing. She had had a close relationship with both of her parents, who had since died, but she felt a lot of guilt toward them due to their having had to worry over her wellbeing in her first marriage. She had therefore distanced herself from her parents during that time. Her former, second husband had been very successful in his work, and he was a charismatic person whom she admired, but also feared. His controlling manner and her need to strive for perfection so that he would not be angry with the children or with her, as well 
as her keeping up the façade of living a happy family life, had taken most of her energy. Ten years prior to coming for treatment, Carey had remarried, this time to a loving man whom she said was very nice and supportive. Her current husband was the only one who knew about her alcohol issues. Her tantrums toward her present husband occurred mostly when she was drunk, and her dismissiveness of him was partly due to his kindness toward her, which she interpreted as weakness.

Carey had never before asked for help to address her alcohol dependence. She had started to drink too much alcohol gradually in her second marriage, and had kept her problems hidden from every one. When she retired from work, her consumption had risen even more and eventually she sought help. After her first contact with the Center for Dependency Disorders, she was able to stop drinking but had one relapse, which was an upsetting experience for her. During the pre-therapy period where alcohol consumption was measured, she did not drink alcohol at all. Hence, her development into dependency was not severe and had not deeply affected her motivational system. In terms of the APT triangles, Carey's formulation was summarized as follows:

Carey's Triangle of Conflict and Triangle of Persons

\begin{tabular}{|c|c|}
\hline $\begin{array}{l}\text { Alcohol, } \\
\text { Self-criticism, } \\
\text { Rage }\end{array}$ & \begin{tabular}{|l} 
Therapist, \\
\end{tabular}$\quad \begin{array}{l}\text { Current } \\
\text { husband, } \\
\text { Sons, Friends }\end{array}$ \\
\hline $\begin{array}{l}\text { Positive feelings toward the self, } \\
\text { Closeness to others } \\
\text { Assertive anger }\end{array}$ & $\begin{array}{l}\text { Second, Former husband, } \\
\text { Parents }\end{array}$ \\
\hline
\end{tabular}

\section{Treatment Plan}

Carey had no prior experience of therapy. She was highly motivated and grateful for the opportunity for change. Carey described her alcohol problems and her insecurity in relating to family and friends as her greatest difficulties. She expressed a wish to become closer to her children and to feel more at ease in social situations. She was especially worried about her uneasy relationship with one of her sons, and she had feelings of guilt about the way her son had been negatively affected by her former marriage and by the divorce that she had eventually obtained. The affect phobias that had to be addressed in therapy were phobias concerning assertive anger, challenging her excessive self-criticism, and getting close to others.

In formulating the core conflict, there was a consensus between Carey and the therapist that these activating affects, and the related issues of self and self-other, had been linked to fear, anxiety, and guilt; and hence these latter emotions had been defensively reduced through excessive alcohol consumption and high levels of self-criticism as well as anger outbursts. In the triangle of persons, her former husband seemed to have played a large part in the development of her affective phobic reactions. The treatment plan was to first restore the positive memories of the loving and supportive relationship between Carey and her parents, to address the guilt feelings toward her sons, and to work through her affect phobia toward self-assertive anger. As 
Carey had secure attachment experiences from her childhood, and was well functioning, we would be able to start defense restructuring from the beginning of therapy.

\section{COURSE OF TREATMENT}

All three patients completed the pre-therapy measurement period, the entire 10-session treatment, and the follow-up measurement period. The rationale for trying the APT-model in relation to alcohol-use problems were discussed and agreed upon together with the patient at inclusion and in session 1. Excessive alcohol use was thus understood as a defense (maladaptive avoidant behavior). In the course of therapy however, talk about alcohol played a minor role since the focus in APT is experiential. Thus the focus of the therapy was on working with the defenses that arose in the session; regulating inhibitory affects; and recognizing, experiencing, understanding, and finally expressing affects adaptively.

\section{Structure of the Affect Phobia Therapy}

The treatment consisted of ten sessions of individual therapy, conducted once a week. The first session lasted 90-120 minutes, and subsequent sessions were 50 minutes long. The sessions were conducted following the manual for Affect Phobia Therapy (APT) (McCullough et al., 2003); and all the sessions were held in Swedish, the native language of the therapist and the three patients. I (the first author) was the therapist for all of the three patients. APT focuses on recognizing, understanding, and regulating affects. The emotional processing in APT treatment begins with defense recognition, proceeds to affect experiencing, and then continues toward affect expression.

In affect phobia therapy generally, therapeutic change occurs through systematic desensitization, i.e., step-wise exposure to the feared affect, preventing the maladaptive avoidant response (response prevention), while regulating the patient's anxiety level (anxiety regulation) and then continuing to expose her or him to the feelings. The therapist exposes the patient to feelings by both asking about specific situations of importance today and also specifically by asking about the patient's history, where needs carried by activating affects were met or unmet. Exposure can be done through imaginative methods, e.g., by a patient describing a scene from memory or in a two-chair exposure (Greenberg, 1984); or in the therapy relationship (with either transference material or manifest material).

The therapist blocks defenses by making the patient aware of the defenses when they occur, using psychoeducation about how the defenses developed and persist, and also pointing out the costs and benefits of the defenses. Techniques used for anxiety regulation are validating and normalizing the inhibitory affects like anxiety, slowing down the exposure by focusing on cognition, attending to the patient's bodily reactions and soothing them with self-care (breathing, touching, images), and the therapist's caring support.

The procedure of systematic desensitization is repeated over and over again until the patient is able to experience the formerly defended against affect. Afterword, the patient and therapist talk about what has taken place, putting words to feelings and understanding the process. In this therapeutic procedure, a new exposure may take place, often in relation to feelings between the patient and therapist. 
(When the patient's symptom level is severe and functioning in everyday life is seriously diminished, and when the patient has insufficient positive feelings toward the self, therapy has to be conducted differently. This is also true when the patient's problem is concerned with impulse control, such as acting out, outbursts of rage, and severe substance abuse or eating disorders. Before defense recognition, affect experiencing, and affect expression are possible, there has to be work on self-restructuring, involving building compassion and care for the self, and on otherrestructuring, involving building adaptive inner images of others. This therapeutic work is closely linked to relational attachment trauma, and thus building trust into the therapeutic relationship will be the first step of therapy. Hence, the change process in therapy will go more slowly and more sessions are needed.)

\section{A. CAREY'S COURSE OF TREATMENT}

\section{Exploring Phase}

$\underline{\text { Session } 1 \text { (90 minutes long) }}$

Starting with her reasons for seeking therapy, Carey described her wish for closeness with family and friends together with her feelings of loneliness and disconnectedness to others. I asked for instances in her everyday life when she had related to family members and friends, including what had happened and what she had felt about herself and about the other person. A core conflict started to form where positive feelings toward the self and closeness to others had been linked to anxiety and guilt, which she avoided through excessive alcohol consumption and high levels of self-criticism. We both understood that Carey had used alcohol as a way of suppressing painful feelings.

In the triangle of persons, Carey's former (second) husband seemed to have played a large part in the development of her affective phobic reactions. There was great motivation to form new, healthier relationships with family members in the present, and I could feel that Carey at this early point in time already held the therapeutic relationship with me in high regard. I explained the rationale of the therapy and how we could use imaginative methods to work with her feelings in relation to important others. Carey was positive towards the therapeutic method and eager to start working for change.

\section{$\underline{\text { Session } 2}$}

In session 2, we established more clearly the link between self-criticism (a defense), developed from inhibitory guilt and anxiety feelings, and its link to experiences in Carey's former marriage. The focus of therapy was now on recognizing the cost of that defense and building motivation for change by augmenting positive, activating feelings toward the self. Thus, one core conflict was established, and the associations to the past and the learning process were understood. In the session I directly expressed my positive regard for and eagerness to do therapeutic work with Carey, and Carey responded by expressing that she wanted change and was ready to work for it. 


\section{Focusing Phase}

\section{$\underline{\text { Session } 3}$}

In session 3 we picked up on the conflict formulation and began work. The focus was on Carey's feelings of guilt toward her deceased parents. I described to Carey how the two-chair technique was conducted and asked if she wanted to try it. Carey said yes, and chose to put her mother in the empty chair. She had no problems in seeing her mother, and she turned to the chair, talking straight to her mother through guided fantasy. She told her mother that she was sorry for causing her pain. She reassured her mother that she had left her husband and now led a happier life. I followed Carey's process closely in the exercise, asking what Carey felt and what she saw in her mother's eyes, prompting Carey to address her mother verbally or with a focus on Carey's emotions, when it was needed to make the process proceed. Carey was filled with feelings of grief. When she was asked to sit in the other chair and take the position of the mother, Carey was filled with feelings of love, and inside her head she heard her mother express loving feelings toward her.

\section{$\underline{\text { Session } 4}$}

On coming into session 4, the first thing Carey told me was that she had experienced a transformed feeling of presence and love in regard to her parents in her current life. She had fantasized talking to them during the week, and she felt that guilt had been cleared away from the relationship between them.

We then focused on Carey's feelings toward her ex-husband. Carey told stories about their life together and how she had stayed in the marriage much too long, feeling unable to act. No violence had taken place. When her anxiety rose, I normalized her incapacitation given the situation she had been in. Carey expressed sorrow and, to some small extent, anger toward her ex-husband. The most painful part for her was thinking about how her son had feared his father and felt unprotected by his mother.

I focused on encouraging Carey to allow herself the experience of feeling pain and guilt. A specific memory emerged where her father had criticized the son for not understanding math. Unfortunately, in retrospect, I did not ask the obvious question of what Carey would have wanted to say or do to her husband, and the opportunity to open up her feelings of anger passed. Still, the focus for the next step in therapy was clear. We needed to focus on assertive anger (an activating affect), which was hindered by Carey's inhibitory feelings of anxiety and fear, feelings which in turn led to Carey's lack of closeness.

\section{$\underline{\text { Session } 5}$}

At the start of session 5, Carey said that she was starting to realize how much her exhusband still affected her. I again suggested and Carey agreed to engage in two-chair work, this time with her former husband in the chair. Carey found it difficult to address him, and I observed that she was guarded. Carey became self-critical, and I used psychoeducation regarding the concept of self-compassion as a way of combatting her self-criticism defense. When her inhibitory feelings of pain and anxiety increased, I asked Cary what the most difficult part of 
addressing her ex-husband was. Carey replied that she thought she would still listen to him and feel controlled by him.'

\section{$\underline{\text { Session } 6}$}

During the week that followed, Carey continued to feel anger and grief in relation to her ex-husband, but in session 6 it was evident that her inhibitory feelings of fear and shame had lessened. Carey said she had told a close relative that she was in therapy and about her alcohol problems. This was a big step for her. She expressed feelings of gratefulness toward me for helping her to change, to be brave, and to become close to others. I responded by focusing on Carey's deepening feelings of closeness in relation to the relative, and the scene when the two women had talked with each other was recreated in therapy. Carey said she felt calm, cherished, and understood by the relative. She felt that the two of them were close and that nothing seemed dangerous. Later, when watching the video of the session with my clinical APT supervisor, I recognized my own affect phobia for positive feelings toward myself and towards closeness to others. My supervisor helped me to realize that work on closeness between Carey and me would have been a particularly appropriate choice of focus, but that my own phobias had interfered with experiential learning that would have benefited Carey.

\section{$\underline{\text { Session } 7}$}

In session 7, Carey worked with feelings of guilt and self-criticism, with her son in the empty chair, in order to relate to how her children had been affected by her first marriage and divorce. Carey confronted her son's anxiety and sadness as a little child. I asked what she wanted to say and do, and Carey went on to comfort her son as she would have wanted to do in real life. In the meta-processing that followed, Carey could feel an acceptance of her own incapacities at the time of the marriage, and forgiveness replaced the self-hatred. I also picked up the thread from the last session and said that I valued the feelings of gratitude that Carey felt toward me, and disclosed my own difficulties in accepting them in at the last session.

\section{$\underline{\text { Session } 8}$}

In session 8 Carey openly talked about the anger that she sometimes expressed in tantrums directed toward her current husband. Since this was something that Carey had not communicated to me before, I told her that I valued the information and understood it as Carey's developing sense of self-compassion as well as trust in me. I used the triangle of conflict concept to help Cary understand her tantrums as a defense against the self-assertive anger that she had never been able to direct toward her ex-husband. During the session, I conducted more anger exposure to her tantrums, and once again I asked what Carey wanted to do and say to her husband, this time regarding her ex-husband.

In my eyes the anger seemed mild, nowhere near the murderous rage that I was ready to see emerge. I urged Carey to explore her bodily impulses, and she clearly conveyed that she did not feel the desire to hurt her ex-husband. She said that she only wanted to resist giving him the upper hand. In an imaginary exercise, I had her pull out a heavy, slimy ball from her belly and to tell her former husband to hold it and feel the weight and the horror of it. She then crushed the ball with her feet and ordered her ex-husband to pick up the pieces. In the meta-process that 
followed, Carey told me that she felt relieved from her former husband's criticism that she had internalized and carried around for so many years. She had the sensation that the pain and the previous constant inner stress had disappeared, a feeling that was sustained during the two last sessions of therapy.

\section{End Phase}

\section{$\underline{\text { Session } 9}$}

In session 9, Carey and I further expressed and processed feelings of tenderness and affection between us. I told Carey how emotionally touched I was by her, and I asked what she thought I felt for her. Carey responded that she thought I felt love and affection toward her, and I confirmed that this was true. The fact that the therapy was ending was talked through. Carey felt happy about what she had received in therapy, and was eager to go out and continue to practice what she had learned. She felt gratitude, and the fact that we were going to part did not make her sad.

\section{$\underline{\text { Session } 10}$}

In session 10, Carey and I gathered together a bunch of keys, symbolizing the tools that she would take with her from therapy to keep using in her life. One represented setting limits, one represented feeling proud of herself and of her accomplishments, one represented being more open toward the important people in her life, and one represented letting herself express joy more openly. Carey said she had noticed that she could talk more freely with her children, and that she could both feel and express love toward her current husband in a way she had not before.

Carey went from engaging in problematic drinking behavior to becoming a social drinker. Just after finishing therapy she went on a trip with her husband. Every evening they drank a glass of champagne or some other drink, but Carey had no craving for more, nor did she find drinking problematic. Hence, Carey could easily let down her concern about drinking excessively since her motivation for change was strong, her family and social network were sound, and she had loving individuals whom she could be close to now that her fear was diminished. Since Carey now could express her needs and feelings more freely and could feel equally valuable compared to others, she did not need alcohol as a means of suppressing painful feelings.

Carey's therapy process had closely followed the steps outlined in APT therapy manual, i.e., first defense recognition, and then the therapist blocking the defenses so that the goal of affect experiencing and affect expression could be reached. Also, in the first phase of therapy, Carey worked on building self-compassion and caring for herself, as well as on building adaptive inner images of her parents and children. These steps are often needed before defense restructuring can take place. 


\section{B. MICHELLE'S ASSESSMENT: PRESENTING PROBLEMS, GOALS, STRENGTHS AND HISTORY}

Michelle was 44 years old, born in Sweden. She was an only child and had suffered greatly from loneliness and feelings of insecurity in her childhood. Michelle grew up in a family where her father was alcohol-dependent and her mother was often away on business trips, which left her feeling alone and unprotected. Her coping strategy was to become a child without needs.

Michelle had a university degree but had difficulty finding a position in her line of work. Currently she was working part-time in another field. Michelle lived with her partner and their nine-year-old child.

The relationship between Michelle and her partner had deteriorated over the years. She lacked love and support from him and felt that he did not value her due to her drinking problems. Her feelings of failure professionally as well as relationally were prominent and Michelle had a wish to live more fully and to exploit her full potential but felt stuck. She felt that she had lost the energy and liveliness that she once had and hoped that therapy would help her back on track. She expressed motivation for change and believed that an affect-oriented therapy would be just right for her.

Michelle's greatest focus was her nine-year-old son, and she described their relationship as loving but shadowed by shame and guilt connected with her alcohol problems. She focused on her fear of talking to her son about her alcohol problems and how that would negatively affect their relationship.

Michelle had been in insight-oriented psychotherapy many years ago, which she said had been helpful in her self-development. Her drinking problem was a well-kept secret from family and friends, and she had contacted the addiction clinic six months ago with the aim of finding a way to control her drinking. Michelle's goal in therapy was to develop her capacity to internally and externally express her feelings, needs, and wishes, instead of diminishing herself. She wondered if she would dare to show her real inner self in therapy.

\section{B. MICHELLE'S CASE FORMULATION AND TREATMENT PLAN}

\section{Formulation}

Michelle had unfulfilled attachment needs related to her upbringing with an alcoholic father and a distant mother, whom Michelle first trusted but who was then unable to satisfy Michelle's basic needs for emotional closeness and safety. This had left Michelle with deep feelings of insecurity and mistrust, which led her to reduce the expression of her own needs.

On the surface, her middle class upbringing was unproblematic, secure, and intellectually stimulating. Her higher education and what later became her work were in the field of arts, where expressing thoughts and feelings was achievable and required, even essential. Hence, Michelle was locked in between the possibility of expressing her feelings to get relief and fulfill her needs, and her fear of what was hidden inside her. She solved the dilemma by diminishing herself and 
displayed a façade of calm and content. Her relationship with her partner had deteriorated and there was no love or support between her and her partner.

As a young adult Michelle and her friends drank a lot. Alcohol was a natural ingredient of social life. Over the years she gradually increased her consumption at home, drinking alone or with her partner. Six months previously she had sought help at the clinic for mothers with alcohol problems in an effort to resolve her drinking problems and not expose her child to the same situation she herself had experienced in childhood. But so far her alcohol consumption had not declined. In terms of the APT triangles, Michelle's formulation was summarized like this:

Michelle's Triangle of Conflict and Triangle of Persons

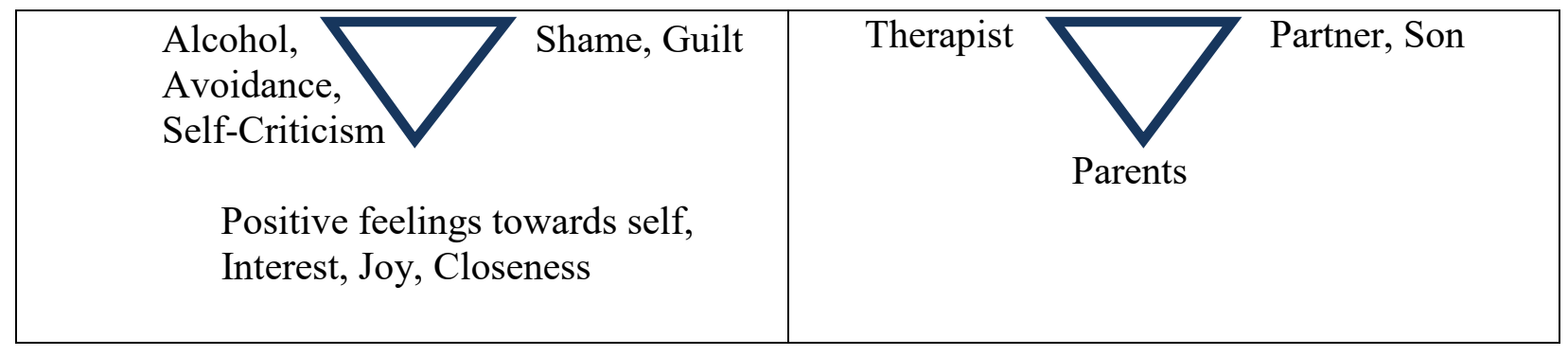

\section{Treatment Plan}

Michelle had undergone insight-oriented therapy many years ago, which she believed had helped her acquire a better self-image. From the description of how she related to herself and others, it was clear that there was more work to be done with issues of self. Michelle wanted help to express her whole emotional repertoire more fully. Not only anger and sadness but also joy and affection toward others were the most difficult feelings for her to express, and she used alcohol to elicit feelings of happiness and self-worthiness. The affect phobias that had to be addressed in therapy concerned fears of positive feelings toward the self, of joy, and of assertive anger.

The core conflict formulation that was articulated between Michelle and me was that she avoided the expression of positive feelings toward the self, self-assertiveness, and asking for support since these elicited guilt, shame, and fear. Her defenses were not taking action and instead drinking to enhance joy.

In the triangle of persons, her mother was the person that she potentially could turn to, but also the one who had abandoned her. This pattern also existed in relation to Michelle's partner, with whom she could not express assertive anger. The treatment plan was to work through the fear of self-assertive anger, pride, self-worth and closeness using imaginative exercises of memories and current life experiences in relation to Michelle's mother, son and partner. I believed defense restructuring could begin at the start of therapy, despite Michelle's difficult upbringing and problems related to positive feelings toward the self and others. Michelle appeared well functioning and was highly motivated to work in experiential psychotherapy. 


\title{
6B. MICHELLE'S COURSE OF TREATMENT
}

\author{
Exploring Phase
}

$\underline{\text { Session } 1 \text { (90 minutes) }}$

Michelle presented with a competent façade and a calm composure. She recognized that her anxiety was associated with affects such as sorrow and anger, and with her own attempts to reduce that anxiety with the help of excessive alcohol consumption. But she also used alcohol to gain feelings of happiness and liveliness.

She experienced intense guilt feelings toward her partner and child associated with her drinking. Her partner had sometimes told her that she had to choose between him and drinking, but had at other times suggested and even created situations where they would share a bottle of wine.

I described the rationale for APT, as well as the goal of linking emotions and thoughts together. I asked Michelle what feelings seemed most important to work on. Michelle talked about her fear of showing anger, and of her tendency to suppress her feelings overall and to disregard her own needs. Drinking helped her both to show emotions and to conceal them. She expanded on this by saying it felt difficult for her to receive positive feedback. Feelings of loneliness and self-criticism were also part of the focus of the first session.

I told Michelle that she could articulate her problems well, and I opened up the possibility that her intellectual ability might be working as a defense against feeling and expressing emotion. Michelle recognized this pattern in herself. The first focus of therapy was thus to understand how fear (an inhibitory affect) and avoidance (a defense) of feelings in general and self-assertive anger (an activating affect) in particular hindered her in her striving to fulfill her own needs.

\section{$\underline{\text { Session } 2}$}

In session 2, Michelle said that she did not know what her own needs and wishes were. How could she strive toward something that she had no knowledge of? We focused on increasing her awareness of her bodily sensations of emotions. Body-focused exercises were introduced. Michelle was prompted to close her eyes, take a few deep breaths, and focus on whatever she could feel in her body. She could feel tenseness in her shoulders and tightness in her chest. I urged her to put her hand on her chest to see if she could soothe her sensations. Michelle said that she experienced some relief. Even so, although the core conflict was understood and formulated early on in therapy, the force of her inhibitory feelings made her jump straight to defenses (not knowing her needs and wishes).

\section{$\underline{\text { Session } 3}$}

In session 3 I provided more psychoeducation regarding how Michelle's fear of affects might have emerged, and how the lack of closeness and a sense of security from attachment figures in her family may have left Michelle feeling vulnerable and alone. 
A memory from her childhood was prompted in an experiential exercise. Michelle was at home with her father, who was sitting in front of the television drinking. She felt so alone. Then her mother arrived home with her suitcase and they hugged for some time, but her mother said nothing. I asked what Michelle would have needed at this moment in time. She replied that she wanted to communicate her feelings and have her mother listen to her. I encouraged her to tell her mother this in the exercise. Michelle found it difficult to find the words, and we ended the exercise. For me, it was important not to make Michelle feel that she had failed, acknowledging that this was the first imaginative exercise in Michelle's therapy. In the meta-processing afterwards, Michelle said that it felt as if she was constantly wearing a mask of protection. I came to think about the friendly smile that was always on Michelle's face.

\section{Focusing Phase}

\section{$\underline{\text { Session } 4}$}

In session 4, we focused on feelings of guilt, especially in relation to Michelle's son. Michelle wished to be able to talk to him about her problems because she knew that this was something that he thought about a lot. She wanted to be honest and to calm him, but she was afraid that their closeness would be damaged. She was also afraid of finding out how her son experienced her drinking. I prompted her to formulate the words she wanted to say to her son, and asked her how she felt when saying them. Instead, Michelle started to talk about how her partner had told her that she would lose her son due to her drinking. This was her greatest fear. I asked Michelle to describe her activities and her contact with her son, and also touched upon Swedish social welfare laws concerning parental rights. In my effort to comfort Michelle, I lost track of the focus of the therapeutic work. Still, at the end of the session Michelle was full of faith that she would have the courage to talk to her son.

\section{$\underline{\text { Session } 5}$}

In session 5, Michelle told me that she had not been succeeded in talking to her son and that this had left her with a sense of failure, which we processed by pointing out the costs and benefits of her defenses. By not talking to him, the benefit was hiding from her feelings of shame and guilt and from the son's justifiable anger at her mother, but the cost was a lack of closeness, which at the moment she could only sustain superficially with her son.

I asked Michelle how she felt about her own mother. Michelle said that she had a great wish to revive the feeling of closeness that they had once had. I introduced imaginative work in relation to her mother. I described how the two-chair technique was conducted and asked if she wanted to try. But Michelle chose to close her eyes and imagine meeting her mother, as I asked questions about what she was feeling and what she wanted to say. She was not ready to be trained in expressing needs and wants explicitly. Still, Michelle told her mother that she had felt abandoned as a child. Her mother was standing in front of her with her arms down to her sides. My aim was to see if Michelle could feel and express feelings of anger to her mother who had not been able to give Michelle what she needed, but the work did not deepen and expressions of anger and sorrow did not emerge. In consultation with my supervisor it became obvious that Michelle's defenses were still too strong for me to help her relinquish them and expose the feelings she was phobic about. 


\section{$\underline{\text { Session } 6}$}

In session 6 we focused on self-criticism, and my aim was to increase Michelle's positive sense of self. Michelle described how she thought that people looked at her critically, but also how her partner explicitly criticized her and put her down. She thought he was unfair. I saw an opportunity to work on self-assertion in relation to the partner. A scene was set up where her partner was sitting in front of the television with the volume turned up loud so it filled the whole apartment, something that Michelle disliked very much. I prompted Nichelle to follow her impulses to act. Michelle fantasized that she lifted the television in her arms, carried it through the room, and threw it out the window. Some self-assertion emerged where Michelle felt a sensation of setting limits toward her partner. She felt her arms being strong, being able to carry the television, and she felt a sense of relief in her chest. Michelle said that she wanted to try and express these feelings in a real-life situation.

\section{$\underline{\text { Session } 7}$}

The next time we met, in session 7, Michelle carried feelings of failure and shame. The energy she had had after our last session had disappeared, as she could not accomplish what she had set out to do and instead had suppressed her feelings with alcohol. Sorrow about her life situation emerged as she thought about how she was missing closeness and support.

I asked what she was longing for. Michelle said that she had a sense that she was alone and that she herself had to fix everything. She longed for support, to lie in someone's lap and be comforted. She experienced both a fear of letting a person get close and also the sorrow that there was no such person in her life who could console her. I asked her to imagine a place where she felt safe and at ease. Michelle described a cottage near the sea where she could hear the waves. She was lying in a bed and rocking herself while listening to the waves. A look of peace fell over her face, but the mask of her permanently smiling face was soon there again.

\section{$\underline{\text { Session } 8}$}

Michelle was resolute about wanting to change her current life situation, but she came into session 8 overwhelmed by how difficult it all felt. She still had strong fears that prevented her from action. It became apparent that her relationship with her partner was impeding her own development. She felt paralyzed. Apart from reducing anxiety, her excessive alcohol consumption helped her momentarily shift her fear into feelings of activation and happiness.

Michelle wanted to separate from her partner, but financial difficulties and her fear (though unwarranted) of losing contact with her son restrained her. I was surprised by this information, as Michelle had not mentioned these matters before. She was stuck, not only in her mind but also in her real-life situation, and she did not see how she would be able to support her son by herself. Once again we worked with self-assertion and with setting limits. In a very concrete manner, Michelle formulated what she wanted to tell her partner and what her actions were going to be. She was going to look for an apartment and she was going to tell her partner that she was fully capable of taking care of her son. I was confident in guiding her through this self-assertive imagery, since she was receiving care at the unit for mothers with alcohol use disorder. 
As described above, Michelle and I were both struggling with wanting the therapy to lead to change. This goal, though, had apparently been set too high. It seemed as if hope was achieved in most sessions, but the foundation for making real progress was too shallow. The focus of therapy, it was now clear, needed to be on body awareness and on strengthening Michelle's capacity to tolerate feelings of anxiety.

\section{End Phase}

\section{$\underline{\text { Session } 9}$}

In session 9, we continued work on body relaxation. Michelle was tense in the shoulders and in her face. She rated the tenseness as 9 on a scale from 1-10. We did a breathing exercise and she was once again at the cottage by the sea. When the exercise ended, Michelle rated her tenseness a little lower and said that it felt as if her face had been cleansed. Two words emerged in her mind: "I want," and I suggested that she should use those two words at the beginning of every sentence, like a mantra during the week to come.

I also asked Michelle to keep her focus on her body and try to detect affective sensations and what they were telling her. As therapy was ending and it was becoming clear to both of us that the work would only get this far. Thus my focus was on helping Michelle to continue keeping her attention on her feelings, to detect them in her body, and to practice not avoiding them but instead listening to what they were telling her.

\section{$\underline{\text { Session } 10}$}

In the last session, Michelle told me that during the week she had had an experience of being able to detect different feelings in her body and to choose which ones to act upon. She was happy to have gained this awareness.

One final time, Michelle and I worked on detecting feelings in her body. When she closed her eyes, her son and her partner appeared. I asked her what words were emerging. There were words of anger toward the partner and words of love toward the son. Michelle could also feel her fear of expressing both anger and love. The conversation turned to what the therapy had and had not given her. Michelle said that she knew she had a lot of work ahead of her, but that she wanted to continue that path. I sat with the feeling that a possible direction of therapy had been discovered too late, that of building motivation for change through the feeling and understanding of how emotions were felt in Michelle's body.

After therapy ended, Michelle's alcohol consumption rose. Alcohol made her come alive, and she was not ready to let go of this short-term relief. Therapy had the function of holding and supporting Michelle, which reduced her alcohol consumption temporarily, but when therapy ended, we had failed to create enough internalized support to make her ready to continue working toward change. Her craving increased and she started drinking more uncontrollably again.

Looking back on the course of therapy, I realized that after the initial mutual understanding of core conflict and defense recognition, we started on working with defense 
restructuring but I realized, alas too late, that Michelle was not ready to give up the defenses. A lot of work was needed for her to just feel the feelings in her body. Work on self-restructuring, i.e., Michelle's building compassion for herself, became the main objective, but was intertwined with defense work and with affect experiencing and affect expression. We also realized that Michelle could not transfer accomplishments she made in therapy to her everyday life. This made her feel ashamed, a feeling that had to be handled with care in therapy. It became evident that Michelle's wish to leave her partner, together with her fear of losing her child, was paralyzing her. Thus, the goals of therapy had to be adjusted.

\section{C. MARY'S ASSESSMENT: PRESENTING PROBLEMS, GOALS, STRENGTHS AND HISTORY}

Mary was 46 years old, born in Sweden, and was living with her husband and their two teenage children. She herself was the oldest of three children, and she described her upbringing as secure but with little room for emotional expression, and with anxiety when conflicts arose. Mary had a university degree in fine arts and worked in her own private company, mostly at home, which meant spending a lot of time on her own. She valued partnerships with colleagues, but at the same time she found it difficult to collaborate. Conflicts with coworkers as well as fear of criticism and social anxiety often became a concern. Although she had many projects, her workload did not generate sufficient income.

Mary described how in the past alcohol had helped her lessen social anxiety, and thus she had experienced positive personal changes related to alcohol. But for several years her alcohol consumption had been problematic, and despite her concern about her physical health and cognitive functioning, her efforts to decrease her drinking had not been successful.

Previous cognitive-behavioral therapy for a simple phobia involving dogs had been successful, and she was motivated for more treatment and longed for a psychotherapeutic contact. She was concerned about guilt in relation to her children and husband, about her professional achievements, and about lack of support from her closest family members. While Mary's husband and children knew of her drinking problems, she kept them as a well-kept secret from her friends and extended family. Mary's goal in therapy was to work with feelings of grief and closeness. She had difficulties connecting to family and friends; for while she had a wish for closeness, she also had a fear of abandonment.

\section{C. MARY'S CASE FORMULATION AND TREATMENT PLAN}

\section{Formulation}

Mary had a seemingly safe and functional upbringing, but still appeared to lack the experience of positive regard from others and safe attachment. Her mother loved infants but seemed to have been less capable of taking care of the growing Mary. When Mary's two younger siblings were born, her mother directed all her energy toward them, leaving Mary feeling desolate and unloved. In the family there was also a sense that individuality was not prioritized. Mary had the feeling that she was not seen as a person, but as part of a group. 
Mary had sought help at the Center for Dependency Disorders due to concerns about how her drinking affected her children and her own health. Regular care with self-monitoring and supportive treatment with a focus on her role as a parent had not succeeded in decreasing her alcohol consumption. Mary had a few negative experiences with alcohol in her adolescence, after which she did not touch it. Then in later adult years, she became a very moderate drinker, but over time, together with her current husband, her intake had risen. When she began having back pain, alcohol had become a perfect remedy for the pain. She also found that alcohol reduced social anxiety. In terms of the APT triangles, Mary's formulation was summarized as follows:

Mary's Triangle of Conflict and Triangle of Persons

Alcohol,
Excessive talk,
Guilt,
Self-criticism,
Attack on others
$\quad \begin{aligned} & \text { Positive feelings toward the self, } \\ & \text { Closeness }\end{aligned}$
$\quad$

\section{Treatment Plan}

As mentioned above, Mary had successfully resolved her dog phobia in a cognitivebehavioral treatment. Now the family had a dog of their own, and Mary was very proud of her accomplishment. Partly because of the positive results of the previous treatment, she put high hopes in the Affect Phobia Treatment for her alcohol use disorder. Mary wished to reduce her drinking to a controlled level. She wanted to stop feeling lonely, to be closer to her family, and to increase feelings of self-worth. The affect phobias that had to be addressed in therapy concerned a fear of positive feelings of self-pride and a fear of closeness to others.

The core conflict formulation that was articulated between Mary and the therapist was that Mary avoided closeness to others and expressions of positive feelings toward the self, since they elicited guilt, shame, and fear. Her defenses were drinking and isolation, as well as anger toward and criticism of others. In the triangle of persons, the pattern had been learned in her family of origin and was continued in relation to teachers and friends. The treatment plan was both to reduce alcohol consumption and to then use memories, imagining, and current life experiences to expose Mary's activating affects. Since Mary had high levels of self-criticism driven by a lack of security and a lack of positive mirroring experiences in childhood, the alliance between her and the therapist had to be strengthened before defense restructuring could begin. 


\title{
6C. MARY'S COURSE OF TREATMENT
}

\author{
Exploring Phase
}

Session 1 (90 minutes long)

In session 1 Mary expressed her nervousness through her body language, which was fidgety and brisk. She talked at length, jumping from one thought to another. She expressed fears that others, including me, would reject her. Mary put the blame on herself for having problems with relationships, and she also expressed sorrow about acting irritably toward others, thereby pushing them away.

Mary said that her use of alcohol distanced her from her family, as she kept to herself so that family members would not sense that she had been drinking. Mary's misuse of alcohol had come about late in life. During a period of back pain she found out that alcohol worked as a relaxant and reduced the pain. She also told me that alcohol had helped her become more sociable and therefore more like the person that she wanted to be. She thought that with the help of alcohol her low self-confidence had been strengthened and she had become more open. I could detect a guarded position when it came to alcohol: Mary wanted to drink socially and had not given up the hope that this would be possible, although she did acknowledge her problematic drinking behavior.

The rationale for APT treatment was described, and I stressed the need to find a focus quickly because the therapy was time-limited. Mary was eager to start therapy, as she thought that the root of her problematic drinking lay in difficult feelings related to how she felt about herself and about how she thought others felt and thought about her. She expressed a wish for closeness (an activating affect) as well as feelings of loneliness and sorrow about her habit of keeping both family and friends at a distance (one of the costs of her defenses).

Mary felt closed off from her family of origin, both wanting and not wanting to talk to or spend time with them. Her mother was an anxious type, so there was no use telling her anything upsetting. The oldest of three siblings, Mary had the sense that her mother had been better suited to caring for very young children and that, when her younger siblings arrived, Mary was put in second place. We started forming a sense of the core conflict together, but Mary's talkativeness and my inability to calm her down left this work unfinished. Shame and self-criticism were clearly evident, as well as avoidance. I identified Mary's constant talking as a defense.

\section{$\underline{\text { Session } 2}$}

In session 2 Mary continued to talk at length although she did tolerate interruptions from me, especially when this pattern of warding off contact and defending against strong feelings was verbalized. We focused on when she had felt alone in the past. Mary described her peer group and her sense of continuously being on the fringe of it. To introduce imaginative work, I suggested that Mary put herself back in a scene from her teenage years where she had felt alone. Mary described an experience from a time in her peer group and gave a colorful and detailed description of the memory, and also described the feelings in her body in visual and kinetic 
language. Mary's sensitivity and low sense of self became apparent in her interpretation of what had happened.

I started to formulate a core conflict together with Mary, where positive feelings toward the self and closeness to others were the activating affects that were warded off by inhibitory feelings of shame. Shame seemed to operate on different levels. First, there was the shame about her drinking, and underneath this was the shame about herself. Mary used avoidance, selfcriticism, and talkativeness as well as over-assertiveness in conversation with others as defensive strategies.

$\underline{\text { Session } 3}$

\section{Focusing Phase}

In session 3, strong feelings of shame and guilt were activated when the session focused on Mary's former workplace, where she had experienced what she described as bullying. It was obvious to me that Mary blamed herself for what had happened. She felt she was difficult to relate to, she took up too much space, and she was just wrong. I asked Mary if she noticed the way she talked about herself. My goal was to elicit Mary's cognitive assets as a way of downregulating inhibitory feelings, as well as to commence the process of increasing self-compassion. Mary answered by telling me about her closest friend who had died a year ago. Mary had not realized how sick the friend was and had thus failed to help her. She felt lonely without her friend, and guilty for not having supported her enough.

I then focused on making Mary feel safe, and on building closeness and support between us, so that we could work with the inhibitory feelings of shame and guilt. I did this by my tone of voice, by my eye contact, and by my reaffirmation that all feelings were allowed in therapy. I also raised the problematic fact that, when I acknowledged feelings of shame and guilt in Mary, this could elicit more of those painful feelings. Mary glanced at me and moved uncomfortably in her chair. Early in the process I was realizing that the therapy had to have a focus other than defense and affect restructuring. Instead, in order to start reducing feelings of shame and guilt. I would have to first build trust and focus on lessening self-criticism.

\section{$\underline{\text { Session } 4}$}

In session 4, Mary's feeling of self-contempt related to experiences of herself as a little girl was the focus. Mary told me how she had experienced shame in relation to her friends and teachers during childhood and adolescence. A vivid memory came into focus. In primary school, the children brought fruit for a snack every day, and Mary once chose to bring a red pepper instead of a fruit. She felt special for coming up with the idea of bringing something different, and she was happy and proud. But when she showed the teachers and classmates the vegetable, she was met with scorn.

The scene was set up in imaginative work, and I followed Mary through the memory, asking what she felt, what she would have needed from the teacher, and what she had wanted to do or say. Mary became quiet and distant, saying that she did not know. It seemed as though the strong inhibitory feelings had made her go straight to the defense of blocking all her emotions. I 
tried to offer support, affirming her feelings and empathizing with her sense of being rejected by the others.

Afterwards, when talking about what had happened, Mary and I set a goal for therapy: that she would be able to stay in the feelings for a short while instead of avoiding them. This became one of our targets. I concluded that guiding Mary through scenes in fantasy and helping her tolerate imagining the adaptive expression of affect would be a sufficient goal of this therapy, considering its time limit. Thus, experiential techniques such as role-playing and the two-chair technique were not methods that I would suggest.

\section{$\underline{\text { Session } 5}$}

When we met the following week in session 5, Mary said that I had been in her thoughts, and this had felt supportive and had caused her to make different decisions about her alcohol use than she normally would have done. She had passed the liquor store and felt the urge to go in, but then I had appeared in her head and she had walked past. I expressed my delight at being in Mary's thoughts and that I had been able to help her. For Mary, rejection was the greatest fear and was what she expected from others.

When I pointed out that Mary was the one distancing herself from her husband and children to prevent them from noticing that she was drinking, she agreed with this description. She wondered whether she kept away so that she would not be the one to be dismissed. The impact of her alcohol dependence was also a factor to consider. Concealing her drinking behavior from family and friends made it easier for her to drink. Mary was keen on finding a psychological explanation rather than having to deal with her drinking problem.

\section{$\underline{\text { Session } 6}$}

In session 6, Mary recounted how she had felt hurt by a colleague. She had become angry and used her rapid way of talking, and in this way prevented any back and forth conversation between them. This incident evoked intense anxiety, and Mary now feared that the colleague would want to stop the collaboration. She once again expressed her fear of rejection.

I initiated psychoeducation on the conflicting feelings that Mary experienced, and specifically differentiated between assertive anger and anger as a defense. We worked on how Mary could be assertive and express her opinions and needs without being judgmental and overly argumentative.

\section{$\underline{\text { Session } 7}$}

In session 7 we continued to focus on reducing self-criticism, and I used techniques of anxiety regulation and tried to keep close contact with Mary in the process. One of Mary's strengths was that she could easily describe her bodily sensations in images: an itching pain in her throat that grew with the feeling of shame, or a hard lump in her belly as an expression of great sorrow.

We focused our attention on the lump in her belly, and I asked questions about how it looked and how it felt to facilitate accessing feelings. As Mary talked, she moved her hands and 
arms in a fidgety way, touching her hair over and over again. Then she became quiet, covering her eyes with her right palm. I understood this as an expression of shame, and asked her what she was feeling. She did not know. I asked: could it be that she was not looking at me because of something she felt about herself? And if so, how might she think that I felt about her? Mary did not respond. I said that I was feeling tender feelings toward her, that I cared about her and wanted her to feel relaxed and able to access with me the hurtful feelings. Thus, the therapeutic work focused on making her feel secure, but I wondered if Mary was really able to benefit from the support offered due to her strong defenses.

\section{$\underline{\text { Session } 8}$}

In session 8 , I focused on what had happened in the previous session. Mary said she recognized her way of shutting down contact and that this happened in stressful situations, for example in conflict situations with her husband. We talked about how best to tackle this in therapy. We decided that I should help Mary heighten her awareness of the dissociation and try not to let herself shut down, which was the term that Mary used herself.

Mary wondered why therapy had to end after ten sessions. She said that therapy was helping her and that after the last session she had felt the aching pain in her belly subside. I responded that I had had the same thought about the therapy being too short for Mary to benefit fully, and the idea arose that, after the present therapy and research study had ended, we might pick up the therapy again.

\section{$\underline{\text { Session } 9}$}

In session 9, we continued the exploration of Mary's tendency to dissociate and, while talking about it, Mary dissociated again. I tried to keep contact by asking Mary where she was in her thoughts and what she felt in her body, and at the same time I tried to regulate her anxiety by validating what was happening and telling her that I was with her.

Mary gazed in the distance and kept quiet, but after some time came back into contact with me, confirming that she was all right but also that what she had just experienced was difficult and important to come to terms with. She once more urgently requested future therapeutic contact as she realized that she needed more help.

\section{End Phase}

In session 10, we went over what the therapy had and had not given Mary. She said that it had been important to realize that she had shut down - or dissociated, as I had described the phenomenon. Mary said that, although she recognized this pattern, she had never before talked about it. She said it felt difficult and dangerous to explore but that it was something she wanted to do. She also said that the fact that I had been positive about a future continuation of therapy was of great value. She felt that I had seen her needs and that she did not feel abandoned, as she had so many times before.

Mary wanted to become a social drinker, although at times she had little hope that it would be possible for her to control her consumption. She had experienced alcohol as a relief 
that lessened tension, making it easier to communicate and relate to others. She was not ready to give up her defenses, as her capacity for self-protection was not strong enough. Therapy might have helped her reduce her binge drinking, but her alcohol dependency was pronounced and it was evident that her motivation to change in terms of her alcohol problems was not strong enough. Because of Mary's need for more than 10 weeks of therapy, we made an agreement that therapeutic contact could be resumed after the study had ended.

Early on in therapy, it became evident that Mary had very strong defenses. Her talkativeness was hard for me to stop, and a clear core conflict formulation together with a shared understanding of her defenses was difficult to fully identify. As described in the APT manual (McCullough et al., 2003), therapy has to begin with self-restructuring and self-other restructuring when the patient has a fragile sense of self. When I tailored the therapy accordingly, I realized that Mary's inhibitory affects of shame and guilt were immense. When using experiential techniques to expose positive feelings toward the self and others, Mary started dissociating and hence, anxiety regulation became crucial. The techniques of APT therapy could not be used and I did not pursue my attempts to put pressure on her defensive system. The goals of therapy could not be reached within the limited time frame. Instead, I focused on building trust and security in the therapy relationship. Since Mary had a talent for visualizations, we used her images to help her get a sense of how pride, trust and closeness could feel, thus holding onto the spirit of APT.

Therapy did resume after the study had ended, and since Mary's alcohol consumption was pronounced and her wish was to drink in a controlled manner, we combined the APT method focusing on self-restructuring and self-other restructuring, with techniques from motivational enhancement therapy (MET), a variant of Motivational Interviewing (Miller, Zweben, DiClemente \& Rychtarik, 1992) developed for the alcohol matching study (Project MATCH, 1997), such as deciding and planning how much Mary could drink weekly, when, and in which setting. She kept an alcohol calendar and reported back at each session. Therapy continued for three years, at times combined with Antabuse (Dislufiram) treatment. Mary could not reach her goals. She drank alone and more than she wanted and it was evident that her motivation to change in terms of her alcohol problems was not strong enough.

\section{THERAPY MONITORING AND USE OF FEEDBACK}

The therapy sessions were recorded on video and shown in weekly clinical supervision with an experienced, peer APT therapist/teacher to ensure adherence to the APT manual as well as to help the therapist clinically adapt the therapy process. To the clients' responses. The development of alcohol and craving parameters during baseline, treatment, and follow-up are presented graphically (see Figure 1). In addition, statistical analysis using chi-square was conducted to calculate differences in two of the alcohol-related measures. Changes in craving over the treatment period were calculated with separate regression lines for each subject, with time in therapy as the independent variable, and craving, measured with PACS, as the dependent variable. Below are also the results from the measures-Psychotherapy Expectations and Experiences (PEX) and the blood test (carbohydrate-deficient transferrin; CDT) - that were only used at inclusion and at follow-up (pre-to-post symptom changes; see second half of Table 2). 


\section{CONCLUDING EVALUATION OF THE THERAPY PROCESS AND OUTCOME}

\section{Quantitative Results}

\section{Carey}

Trajectories of alcohol and craving. As shown by Table 2, Carey had less heavy drinking (HED) at follow-up compared to the three months' recall before inclusion (pre-baseline), and less consumption (CONS) overall when comparing pre-baseline to follow-up. Table 2 shows that craving, measured with PACS was reduced from pre-baseline to follow-up. The regression line for Carey showed that craving went down as therapy progressed (beta $=-.724 ; p=.018$ ).

As shown by the graphs, Carey stopped drinking even before the baseline period began and continued to generally refrain from alcohol consumption during the treatment period. Her craving steadily went down during therapy, and she realized that she could go back to being a social drinker. Hence, her days with alcohol consumption increased after therapy termination, although no days of binge drinking occurred.

Pre- to post-symptom changes. As seen in Table 2, For Carey, affect phobia was reduced by an elevation in her score, from 52 to 78 ( $\geq 72$ constitutes adaptive affective capacity). She had a statistically and clinically significant change on OQ-45 distress-and-impairment scores from 107 at inclusion to a score of 34 at follow-up, with the final score well below the cut-off for the non-patient range; ( $\geq 63-64)$. Carey had a CDT value of 1.60 at inclusion and 0.90 at follow-up.

\section{$\underline{\text { Michelle }}$}

Trajectories of alcohol and craving. As shown in Table 2 Michelle had less heavy episodic drinking (HED) at follow-up compared to the three months' recall before inclusion (prebaseline). Table 2 shows that craving, measured with PACS, was reduced from pre-baseline to follow-up. The regression line for Michelle showed that craving stayed at the same level as therapy proceeded (beta $=.008 ; p=.983$ ). Michelle's binge drinking was reduced during baseline and during the treatment period. As shown in Figure 1, in the last week of follow-up, her drinking suddenly increased to the same level as before baseline; and her cravings and drinking patterns followed each other closely during the whole period.

Pre- to post-symptom changes. For Michelle, the affect phobia scores went from 57 to 51 , showing slightly more affect phobia at follow-up compared to at inclusion. Her distress-andimpairment scores on OQ-45 remained in the clinical range with no statistically reliable change (from 106 to 99). Michelle, who had a blood CDT value of 3.00 at inclusion $(>2.00$ is considered an elevated value), failed to take a blood test at follow-up (see Table 2).

$\underline{\text { Mary }}$

Trajectories of alcohol and craving. As shown by Table 2, Mary had less heavy episodic drinking (HED) at follow-up compared to the three months' recall before inclusion (prebaseline), and less consumption (CONS) overall when comparing pre-baseline to follow-up. 
Table 2 shows that craving, measured with PACS, was reduced from pre-baseline to follow-up. The regression line for Mary showed that there was a decreasing trend in craving during therapy, but the results were not significant (beta $=-.237 ; p=.509$ ). For Mary, there was a positive trend where her episodic binge drinking (HED) became less frequent from week seven in therapy and onward into the follow-up period, although she was still drinking on most days (see Figure 1). Her craving was reduced slightly.

Pre- to post-symptom changes. For Mary, affect phobia was reduced from 60 to 70 (Table 2), although her final score was still below the adaptive affective capacity range of 72 or higher). Her scores on OQ45 also improved from inclusion to follow-up (from 66 to 54) and reached the non-patient range, but the change was too small to be considered a statistically reliable change $(>14)$ according to the manual (Lambert et al., 1996). Mary had a CDT value of 1.30 at inclusion and 0.80 at follow-up, both below the $>2.00$ indicated of an elevated value.

\section{What Carey's Case Tells Us About the Potential of Using the Short-Term APT Model}

Carey stopped drinking before the baseline period started and started drinking socially and without problems at the end of therapy. Her craving was reduced during and after treatment. Carey had less heavy episodic drinking (HED) after treatment compared to the three months' recall before inclusion, as well as decreased levels of alcohol in her blood as measured with CDT. Affect phobia as measured with the Affect Phobia Test was reduced, reaching adaptive levels of affective behavior at follow-up. She also showed symptom reduction as measured with OQ-45.

Carey appeared to have a predominantly secure attachment pattern. Early in therapy she re-established and deepened the loving and supporting bond between herself and her dead parents. Carey showed from the start that she had trust in the therapeutic work that we were doing together, and we created a very good therapeutic alliance. Carey was also very motivated for change. Strong alliance and motivation are pre-requisites for APT in a short-term format. Carey's life circumstances were stable, and when she dared to start leaning on her husband, he was there to support her. Carey's alcohol consumption rose at the end of treatment and at followup. Nevertheless, as shown in the dramatic Affect Phobia Test and OQ-45 results, she made great progress in reducing affect phobia and psychiatric symptoms, including interpersonally and in social role functioning. Carey experienced and expressed affects more freely and she formulated and pursued her own wants and needs.

\section{What Michelle's Case Tells Us About the Limitations of Using the Short-Term APT Model}

Michelle reduced her consumption during therapy but when therapy ended she returned to the same consumption level as before treatment. Nevertheless, she had less heavy episodic drinking (HED) after treatment compared to the three months' recall before inclusion, and less consumption overall comparing pre-baseline to follow-up. Her craving was reduced before treatment commenced and continued on a low level until treatment ended, but increased again shortly after that. 
Michelle's life circumstances gave her too little support to start an intensive therapy in a short-term format. Michelle reported more affect phobia at follow-up and she also had elevated psychiatric symptom levels. Importantly, therapy had the function of holding and supporting her but she was not able to transfer to real life the therapy achievements in the realm of experiencing and expressing affects and pursuing adaptive wants and needs.

From Michelle's presentation in therapy, I formed the clinical impression that there were fragile personality structures behind her mask of competence, with many features of avoidant attachment styles as well as pronounced self-criticism. Thus, more time was needed to create security in the therapy process and to work with self-compassion. It took some time for me to understand how deeply insecure Michelle was, and this was one reason why I had commenced defense work before Michelle was ready for it. I had assumed that Michelle would be receptive to imaginative work because of her professional field of interest, but I realized too late that her fear of experiencing emotions was too great to proceed with such work.

\section{What Mary's Case Tell Us About the Limitations and Potential of Using the APT Model}

Mary had less heavy episodic drinking (HED) after treatment compared to the three month recall before inclusion, and less consumption overall when comparing pre-baseline to follow-up. Also, she had decreasing alcohol levels in her blood as measured with CDT, but therapy did not help her decrease her drinking. Her chemical dependency on alcohol was too great and her craving was only minimally reduced. Hence, Mary's alcohol use problem could not only be understood as a defense.

Mary's level of affect phobia as well as her psychiatric symptom levels on the OQ-45 were reduced, even though the latter did not meet the criteria for statistically reliable change.

Mary had a fragile personality structure with many features of ambivalent and avoidant attachment styles, and pronounced self-criticism. Before Mary could fully use an intensive shortterm therapy format, more work had to be done on building trust between Mary and me. The short-term format of APT could not help her experience affect without dominant fear, nor did it aid her in expressing wants and needs in a regulated manner. Therapy did give her a sense of security and hope, and she was motivated to continue in therapy toward change.

\section{Cross Case Comparisons}

When comparing the three cases some aspects related to positive versus negative outcome stand out. A person with a high-level of alcohol dependency, as diagnosed with DSM-5 criteria and measured by alcohol consumption in grams per day, will not be helped with their alcohol problem in short-term APT, as in the case of Michelle and Mary. Instead, treatments that directly address the alcohol problem, unlike APT that focuses on working with emotions, will be needed. Thus, considering the main objectives of APT in the short-term format, an appropriate patient can't possess intrusive personality problems and needs to have access to positive feelings for self and positive feelings for others. This was the case for Carey. In APT it is important for the therapist and patient to find and work with imaginative methods that fit the individual patient, 
which we did in all three therapies, but with Michelle it took a longer time to find the right methods. This slowed down the course of her treatment.

\section{Role of Change Mechanisms and Common Factors}

In affect-focused experiential psychotherapy, a good working relationship between patient and therapist is essential. A strong emotional bond (Bordin, 1979) will support the patient's exploration of internal experiences and the expression of affect. When the patient feels accepted and safe and in agreement with the therapist on tasks and goals, the intense work can begin (Greenberg \& Safran, 1989).

The working alliance was not measured in the present cases, but clinically it was evident that Carey and I had a strong alliance right from the start. She understood the method, was ready to try it, and trusted me as a companion who would help her reach her goal. A good therapeutic alliance facilitates working with attachment-related aspects of the patient's psychological functioning, i.e., those related to sense of self and sense of others. The therapist as a person and the bond between patient and therapist is of the utmost importance in this process. Since lack of positive feelings for the self and others were central issues for Michelle and Mary, the alliance was also very important but more time was needed for building trust both in the method and in me as the therapist. Mary viewed my offer of continued therapy after the study period as a great gift. Since I had seen her suffering, I wanted to give her my support.

\section{Methodological and Research Considerations}

Case studies make it possible to assess the therapy process extensively. In between each session, I watched the video recording of my previous session, although the descriptions of the therapeutic processes were written after the study had ended.

The primary outcome measure in the study was heavy episodic drinking (HED), but the measure gives only limited information on consumption. A better indicator would have been intake of alcohol, measured in grams per day, which I would recommend for future studies. This measure will give a more accurate description of the actual alcohol consumption. Furthermore, the study shows the need to use several alcohol- and non-alcohol-related measures through treatment. For example, Carey's alcohol consumption rose at the end of treatment and at followup because of an interest in nonproblematic social drinking; but this was not quantitatively captured in the measures. Yet overall, Carey made great progress in reducing affect phobia and psychiatric symptoms, and in increasing interpersonal and social role functioning.

Only one therapist conducted the treatments, which is recommended in a small $\mathrm{N}$ design. The therapist was also one of the researchers in the study. This raises questions about subjectivity/objectivity, although this concern was in part controlled for by the use of detailed qualitative descriptions of therapy process and outcome together with standardized quantitative measures. There is obviously an allegiance to the therapeutic method but also an ethical stance both as a researcher and as a therapist. Knowledge about the patient group and the APT method made the first author the most suitable person to act as the treating psychotherapist in this project. The therapist never intervened in the data collection, which was based on patients' selfreports and administered by a nurse. 
The next step in the research process will be to investigate APT for alcohol use disorder in an open trial or in a randomized controlled trial with larger samples, where multiple therapists conduct the therapies - although it should be noted that therapist allegiance to a researchpredicted outcome is also an issue in these types of study designs. Also, while some information about how the effects of treatment was obtained with the four-week follow-up period, a longer follow-up would have provided additional valuable information.

Group therapy is common in treatments for alcohol use disorder. Developing APT into a group format would seem to be particularly productive since affects are a way for people to communicate and connect to each other. For a preliminary, promising effort to develop APT in a group format, see Frankl (2017).

\section{Clinical Implications}

The results from these three case studies provide a first indication that APT is a tolerable and feasible treatment for patients with ongoing alcohol use disorder. The three patients completed participation from inclusion to follow-up with no adverse effects. The results of the study are mixed, and the hypothesis that heavy episodic drinking would subside during the time in therapy did not hold true for all patients. Instead, the three patients had different trajectories of alcohol consumption and craving. Differences in treatment results may also be due to the patients' level of chemical dependency. One of the patients, Mary, seems to have had a greater chemical dependency, a clinical conclusion based on my knowledge of her derived from our therapy that took place after the 10-session APT therapy ended. A thorough assessment before starting APT treatment for patients with alcohol dependency is necessary and can result in recommendations of other complementary treatment methods, such as Response Prevention and Motivational Enhancement, or a combination of these modalities for enhanced therapy results.

Affect phobia was reduced for Carey and Mary, and both showed correlated reductions in psychiatric symptoms on the OQ-45 and in the CDT (carbohydrate-deficient transferrin) levels in their blood, indicating a reduction in average alcohol consumption during a period of one to four weeks prior to testing. Thus, there is some evidence for the view that patients who can achieve a more adaptive use of affects might be more able to decrease their defenses, such as alcohol misuse, and to increase overall better functioning. This may also illustrate the crucial role that emotions play in our everyday life (Ekman, 1992; Levenson, 2011; Panksepp \& Watt, 2011). Unfortunately, we do not have data on Michelle since she failed to give a blood sample after treatment.

In my clinical impression and in the patients' description of their problems, all three therapies support the idea that alcohol may be used as a defense against painful affects; and that a patient's intellectual understanding of this defensive strategy will not be sufficient to change the behavior pattern. The reason why the three cases have different treatment results is most probably multifaceted and influenced by both personality factors - such as attachment style, resilience, and sensitivity to stress - and by current life situations, for example, presence or lack of support from a partner.

Previous research (Kadden et al., 2001a; Kadden et al., 2001b; Kadden et al., 1989; Litt et al., 1992; Ojehagen et al., 1992; Sandahl et al., 1998) shows that psychodynamic therapy for 
alcohol use disorder can be conducted with short periods of abstinence (less than 3 months) from alcohol prior to the start of therapy. However, in individual psychodynamic psychotherapy it traditionally has been the practice to have a longer period of abstinence from alcohol (3-6 months) before the start of therapy.

The present cases illustrate that APT treatment for patients with mild to moderate alcohol use disorder and affect phobia can begin therapy without a prolonged period of abstinence from alcohol. In the current study, an inclusion criterion was seven sober days preceding the baseline measurement. Clinically, this requirement will hinder patients from entering psychotherapy, when instead treatment should be easily accessible. As an alternative, a biological marker can ensure that the patient does not have an extreme daily consumption of alcohol that might impede the therapy process. Overall, the results with the cases of Carey, Michelle, and Mary suggest that short-term APT treatment is appropriate for the same types of mild-to-moderate alcohol use disorder patients who have been traditionally assigned to Response Prevention and Motivational Enhancement treatments.

APT treatment in itself does not contain strategies for helping the patient refrain from drinking; and as the exposure to activating affects initially triggers anxiety, which in turn activates defenses like craving for alcohol, it is important to incorporate safety structures in the treatment. Specifically, the therapist must ensure that exposure in treatment is balanced and always carried out together with anxiety regulation. Also, the patient should be aided in building non-destructive defenses as a replacement to excessive alcohol consumption. In addition, psychoeducation and skill-building on how to handle craving could be integrated in the APT treatment. It would also seem important for the therapist and patient to examine how to use the patient's social network when needed.

The results of the three case studies suggest that for some patients diagnosed with alcohol use disorder, like Carey, APT can be a valuable treatment; but the short duration of ten sessions may not be sufficient for others, like Michelle and Mary. Ten weeks of therapy is a short-term treatment, especially compared to other psychodynamic psychotherapies for alcohol dependence. For example, in the study by Ojehagen et al. (1992), the treatment continued for either one or two years weekly. The interactional group therapy study was conducted during 26 sessions (Kadden, Litt, Cooney, Kabela, \& Getter, 2001b). In the Sandahl et al. study (1998), psychodynamic group therapy was conducted once a week, with 15 sessions each lasting 90 minutes.

Because Relapse Prevention and Motivational Enhancement therapies have shorter treatment periods, our intention in the present study was to give APT treatment for a similar length of time. An alternative treatment plan could be a longer treatment period or an initial treatment phase where self and self-other issues are addressed and self-compassion is enhanced before initiating defense-relinquishing, affect-experiencing, and affect-expression (McCullough et al., 2003; McCullough Vaillant, 1997). Process studies have shown the importance of selfcompassion for the reduction of psychiatric symptoms and of interpersonal and personality problems in APT treatment (Berggraf et al., 2014; Schanche et al., 2011). When self-criticism is a major issue for the patient, this has to be addressed in depth, which will lengthen the treatment period. In clinical practice; and thus there should be more flexibility in the length of treatment. For Michelle, heavy episodic drinking assumed a high level just at the end of therapy. Resumed 
drinking due to the sudden discontinuation of therapy could be avoided by prolonging therapy in the form of booster sessions. However, in the prolonged therapy with Mary, work on lessening self-criticism was aggravated by her difficulties in tolerating adaptive guilt feelings for how her alcohol dependence affected her children.

Finally, as described at the beginning of this paper, the cases of Carey, Michelle, and Mary were in effect randomly selected from a group of individuals who met the following criteria: older women with mild-to-moderate AUD which began over the age of 30, with no other substance abuse, with a stable social situation, and who had voluntarily sought treatment for the first time for their AUD at the beginning of the treatment. It would seem that a sizable population of individuals with AUD would meet these criteria, and it is important to see that at least one of the three, Carey, was dramatically and unequivocably helped by the short-term APT treatment. Generalizing, Carey's success provides some evidence that a number of individuals in this population could benefit substantially from short-term APT treatment.

\section{REFERENCES}

Abramowitz, J. S., Deacon, B. J., Whiteside, S. P. H. (2010). Exposure therapy for anxiety: Principles and practice. New York: Guilford Press.

Aurora, P., \& Klanecky, A. (2016). Drinking motives mediate emotion regulation difficulties and problem drinking in college students. The American Journal of Drug and Alcohol Abuse, 1-10. http://doi.org/10.3109/00952990.2015.1133633

Aviezer, H., Trope, Y., \& Todorov, A. (2012). Body cues, not facial expressions, discriminate between intense positive and negative emotions. Science, 338, 1225-1229. http://doi.org/10.1126/science. 1224313

Babor, T. F. (1992). Types of Alcoholics, I. Archives of General Psychiatry, 49, 599. http://doi.org/10.1001/archpsyc.1992.01820080007002

Babor, T. F., \& Caetano, R. (2006). Subtypes of substance dependence and abuse: implications for diagnostic classification and empirical research. Addiction , 101, 104-10. http://doi.org/10.1111/j.1360-0443.2006.01595.x

Berggraf, L., Ulvenes, P., Hoffart, A., McCullough, L., \& Wampold, B. (2014). Growth in sense of self and sense of others predicts reduction in interpersonal problems in short-term dynamic but not in cognitive therapy. Psychotherapy Research, 24, 456-469. http://doi.org/10.1080/10503307.2013.840401

Berglund, M., Thelander, S., Salaspuro, M., Franck, J., Andréasson, S., \& Ojehagen, A. (2003). Treatment of alcohol abuse: An evidence-based review. Alcoholism, Clinical and Experimental Research, 27, 1645-1656. http://doi.org/10.1097/01.ALC.0000090144.99832.19

Brown, S., \& Yalom, I. (1977). International group therapy with alcoholics. Journal of Studies on Alcohol, 38(3), 426-56. Retrieved from http://www.ncbi.nlm.nih.gov/pubmed/859331

Clinton, D., \& Sandell, R. (2003). PEX-psychotherapy expectations and experience questionnaire. Unpublished manuscript.

Cloninger, C. (1981). Inheritance of Alcohol Abuse. Archives of General Psychiatry, 38, 861. http://doi.org/10.1001/archpsyc.1981.01780330019001

Cooney, N. L., Kadden, R. M., Litt, M. D., \& Getter, H. (1991). Matching alcoholics to coping skills or interactional therapies: Two-year follow-up results. Journal of Consulting and Clinical Psychology, 59(4), 598-601. Retrieved from 
http://ovidsp.tx.ovid.com.proxy.kib.ki.se

Cooper, M., Frone, M., Russell, M., \& Mudar, P. (1995). Drinking to regulate positive and negative emotions: a motivational model of alcohol use. Journal of Personality and Social Psychology, 69(5), 990-1005. Retrieved from http://www.ncbi.nlm.nih.gov/pubmed/7473043

Dvorak, R. D., Sargent, E. M., Kilwein, T. M., Stevenson, B. L., Kuvaas, N. J., \& Williams, T. J. (2014). Alcohol use and alcohol-related consequences: associations with emotion regulation difficulties. The American Journal of Drug and Alcohol Abuse, 40, 125-30. http://doi.org/10.3109/00952990.2013.877920

Ekman, P. (1992). An argument for basic emotions. Cognition and Emotion, 6, 169-200. http://doi.org/10.1080/02699939208411068

Fishman, D. B., Messer, S.B., Edwards, D.J.A., \& Dattilio, F.M. (2017). Case studies within psychotherapy trials: Integrating qualitative and quantitative methods. New York: Oxford.

Flannery, B. A., Volpicelli, J. R., \& Pettinati, H. M. (1999). Psychometric properties of the Penn alcohol craving scale. Alcoholism: Clinical and Experimental Research, 23, 1289-1295. http://doi.org/10.1111/j.1530-0277.1999.tb04349.x

Frankl, M. (2017). Psychotherapy for substance use disorders--the importance of affects. Unpublished doctoral dissertation, Faculty of Arts and Sciences, Linkoping University, Linkoping, Sweden. available at: http://liu.diva-portal.org/smash/get/diva2:1159275/FULLTEXT01.pdf.

Frankl, M., Philips, B., Berggraf, L., Ulvenes, P., Johansson, R., \& Wennberg, P. (2016). Psychometric properties of the Affect Phobia Test. Scandinavian Journal of Psychology, 57, 482-488. http://doi.org/10.1111/sjop.12308

Frankl, M., Philips, B., \& Wennberg, P. (2014). Psychotherapy role expectations and experiences: Discrepancy and therapeutic alliance among patients with substance use disorders. Psychology and Psychotherapy: Theory, Research and Practice, 87(4), 411424. http://doi.org/10.1111/papt.12021

Hesselbrock, V. M., \& Hesselbrock, M. N. (2006). Are there empirically supported and clinically useful subtypes of alcohol dependence? Addiction, 101, 97-103. http://doi.org/10.1111/j.1360-0443.2006.01596.x

Kadden, R. M., Cooney, N. L., Getter, H., \& Litt, M. D. (1989). Matching alcoholics to coping skills or interactional therapies: Posttreatment results. Journal of Consulting and Clinical Psychology, 57(6), 698-704. Retrieved from http://ovidsp.tx.ovid.com.proxy.kib.ki.se

Kadden, R. M., Litt, M. D., Cooney, N. L., Kabela, E., \& Getter, H. (2001a). Prospective matching of alcoholic clients to cognitive- behavioral or interactional group therapy. Journal of Studies on Alcohol and Drugs, 62(3), 359.

Kadden, R. M., Litt, M. D., Cooney, N. L., Kabela, E., \& Getter, H. (2001b). Prospective matching of alcoholic clients to cognitive-behavioral or interactional group therapy. Journal of Studies on Alcohol, 62(3), 359-369. http://doi.org/10.15288/jsa.2001.62.359

Khantzian, E. J. (1997). The self-medication hypothesis of substance use disorders: a reconsideration and recent applications. Harvard Review of Psychiatry, 4, 231-44. http://doi.org/10.3109/10673229709030550

Khantzian, E. J. (2012). Reflections on treating addictive disorders: a psychodynamic perspective. The American Journal on Addictions / American Academy of Psychiatrists in Alcoholism and Addictions, 21, 274-279. 
Kuntsche, E., Knibbe, R., Gmel, G., \& Engels, R. (2005). Why do young people drink? A review of drinking motives. Clinical Psychology Review, 25, 841-61.

http://doi.org/10.1016/j.cpr.2005.06.002

Lambert, M. J., Burlingame, G. M., Umphress, V., Hansen, N. B., Vermeersch, D. A., Clouse, G. C., \& Yanchar, S. C. (1996). The reliability and validity of the outcome questionnaire. Clinical Psychology \& Psychotherapy, 3, 249-258. http://doi.org/10.1002/(SICI)10990879(199612)3:4<249::AID-CPP106>3.0.CO;2-S

Leggio, L., Kenna, G., Fenton, M., Bonenfant, E., \& Swift, R. (2009). Typologies of alcohol dependence. From Jellinek to genetics and beyond. Neuropsychology Review, 19, 115129. http://doi.org/10.1007/s11065-008-9080-z

Levenson, R. W. (2011). Basic emotion questions. Emotion Review, 3, 379-386. http://doi.org/10.1177/1754073911410743

Litt, M. D., Babor, T. F., DelBoca, F. K., Kadden, R. M., \& Cooney, N. L. (1992). Types of alcoholics, II. Application of an empirically derived typology to treatment matching. Archives of General Psychiatry, 49, 609-14. Retrieved from http://www.ncbi.nlm.nih.gov/pubmed/1322118

Malan, D. (1995). Individual Psychotherapy and the Science of Psychodynamics (2nd ed). Oxford: Butterworth-Heinemann. Retrieved from http://www.adlibris.com/se/bok/individual-psychotherapy-and-the-science-ofpsychodynamics-9780750623872

Marlatt, G. A., \& Donovan, D. M. (2005). Relapse prevention: Maintenance strategies in the treatment of addictive behaviors. (2nd ed.). New York: Guilford Press.

McCullough, L., Berggraf, L., \& Ulvenes, P. G. (2010). The affect phobia test. Unpublished manuscript, Modum Bad Research Institute, Vikersund, Norway.

McCullough, L., Kuhn, N., Andrews, S., Kaplan, A., Wolf, J., \& Hurley, C. (2003). Treating affect phobia: A manual for short-term dynamic psychotherapy. New York: Guilford Press.

McCullough Vaillant, L. (1997). Changing character: Short-term anxiety-regulating psychotherapy for restructuring defenses, affects, and attachment. New York: Basic Books.

Miller, W. R., \& Rollnick, S. (2002). Motivational interviewing: Preparing people for change (2nd ed.). New York: Guilford Press.

Miller,W. R., Zweben, A., DiClemente, C. C., \& Rychtarik, R. C. (1992). Motivational enhancement therapy manual: a clinical research guide for therapists treating individuals with alcohol abuse and dependence. (Vol. ProjectMATCHMonograph Series, Vol. 2). Rockville,,Maryland: National Institute on Alcohol Abuse and Alcoholism.

Ojehagen, A., Berglund, M., Andersson, K., Nilsson, B., \& Skjaerris, A. (1993). A randomized study of long-term out-patient treatment in alcoholics, 27(6).

Osborn, K., Ulvenes, P., Wampold, B., \& McCullough, L. (2014). Creating change through focusing on affect: Affect Phobia Therapy. In N. Thoma \& D. McKay (Eds.), Working with emotions in cognitive behavioral therapy: Techniques for clinical practice (pp. 146174). New York: Guilford Press.

Panksepp, J., \& Watt, D. (2011). What is basic about basic emotions? Lasting lessons from affective neuroscience. Emotion Review, 3, 387-396. http://doi.org/10.1177/1754073911410741 
Project MATCH Research Group. (1997). Matching alcoholism treatments to client heterogeneity: treatment main effects and matching effects on drinking during treatment. Journal of Studies on Alcohol, 59, 631-9.

Sandahl, C., Herlitz, K., \& Ahlin, G. (1998). Time-limited group psychotherapy for moderately alcohol dependent patients : A randomized controlled clinical trial. Psychotherapy Research, 8, 361-378. http://doi.org/10.1080/10503309812331332467

Schanche, E., Stiles, T., McCullough, L., Svartberg, M., \& Nielsen, G. (2011). The relationship between activating affects, inhibitory affects, and self-compassion in patients with cluster c personality disorders. Psychotherapy, 48, 293-303. http://doi.org/10.1037/a0022012

Sharpe, P. C. (2001). Biochemical detection and monitoring of alcohol abuse and abstinence. Annals of Clinical Biochemistry, 38, 652-664. http://doi.org/10.1258/0004563011901064

Sobell, L. C., \& Sobell, M. B. (1992). Time line follow back. A technique for assessing selfreported alcohol consumption. In R. Litten \& J. Allen (Eds.), Measuring Alcohol Consumption: Psychosocial and Biochemical Methods. (pp. 41-72). New Jersey: Humana Press.

Stapinski, L. A., Edwards, A. C., Hickman, M., Araya, R., Teesson, M., Newton, N. C., ... Heron, J. (2016). Drinking to Cope: a latent class analysis of coping motives for alcohol use in a large cohort of adolescents. Prevention Science : The Official Journal of the Society for Prevention Research. http://doi.org/10.1007/s11121-016-0652-5

Stiles, W. B. (2009). Responsiveness as an obstacle for psychotherapy outcome research: It's worse than you think. Clinical Psychology Science and Practice, 16, 86-91. https://doi.org/10.111/j.1468-2850.2009.01148.x

Svartberg, M., Stiles, T. C., \& Seltzer, M. H. (2004). Randomized, controlled trial of the effectiveness of short-term dynamic psychotherapy and cognitive therapy for cluster $\mathrm{C}$ personality disorders. The American Journal of Psychiatry, 161, 810-817. http://doi.org/http://dx.doi.org/10.1176/appi.ajp.161.5.810

Tomkins, S. S. (1962). Affect, imagery, consciousness: Volume I. Positive affects. New York: Springer.

Ulvenes, P., Hoffart, A., Stiles, T., Svartberg, M., McCullough, L., \& Wampold, B. (2012). Different processes for different therapies: Therapist actions, therapeutic bond, and outcome. Psychotherapy, 49, 291-302. http://doi.org/10.1037/a0027895

Wennberg, P., \& Bohman, M. (1998). The timeline follow back technique: Psychometric properties of a 28-day timeline for measuring alcohol consumption. German Journal of Psychiatry, 2, 62-68. Retrieved from http://www.gjpsy.uni-goettingen.de

Wennberg, P., Philips, B., \& de Jong, K. (2010). The Swedish version of the outcome questionnaire (OQ-45): Reliability and factor structure in a substance abuse sample. Psychology and Psychotherapy: Theory, Research and Practice, 83, 325-329. http://doi.org/10.1348/147608309X478715

Windle, M., \& Scheidt, D. M. (2004). Alcoholic subtypes: are two sufficient? Addiction, 99, 1508-19. http://doi.org/10.1111/j.1360-0443.2004.00878.x

Winston, A., Laikin, M., Pollack, J., Samstag, W., McCullough, L., \& Muran, J. (1994). Shortterm psychotherapy of personality disorders. American Journal of Psychiatry, 151, 190194. Retrieved from http://dx.doi.org/10.1176/ajp.151.2.190 
Affect Phobia Therapy for Alcohol Dependence: The Cases of "Carey," "Michelle," and "Mary"

M. Frankl, P. Wennberg, L. Berggraf, \& B. Philips

Pragmatic Case Studies in Psychotherapy, http://pcsp.libraries.rutgers.edu

Volume 15, Module 3, Article 1, pp. 214-257, 01-09-20 [copyright by authors]

Table 1. The Triangle Form

(This form was developed by Leigh McCullough and her colleagues. The forms can be used by the therapist or the patient. For more details, go to: https://www.affectphobiatherapy.com/forms/).

Patient

Core formulations (in terms of affect phobia)

\section{DEFENSE}

....and this is what $\mathrm{I}$

do/feel/think to avoid

that:

1 .

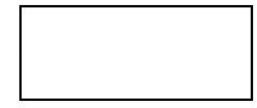

2.

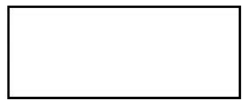

3.

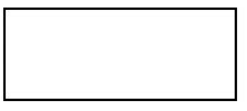

1.

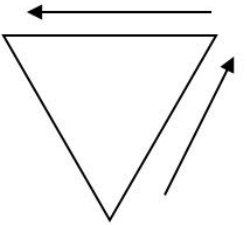

WISH/WANT/

FEEL/NEED

This is what I

wish/want/

feel/need...

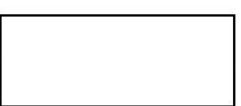

2.

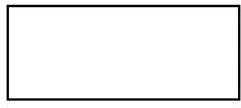

3.

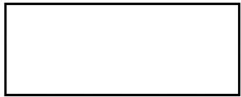

THERAPIST
ANXIETY/FEAR/

SHAME/DISGUST

...but I am so a fraid

this will happen...

1.

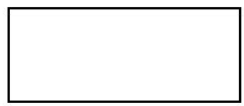

2.

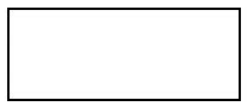

3.

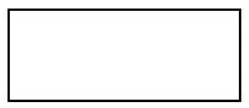


Affect Phobia Therapy for Alcohol Dependence: The Cases of "Carey," "Michelle," and "Mary"

M. Frankl, P. Wennberg, L. Berggraf, \& B. Philips

Pragmatic Case Studies in Psychotherapy, http://pcsp.libraries.rutgers.edu

Volume 15, Module 3, Article 1, pp. 214-257, 01-09-20 [copyright by authors]

Table 2. Data from Self-Report Questionnaires and Interviews at Different Times

\begin{tabular}{|c|c|c|c|c|}
\hline SCALE & TIME POINT & CAREY & MICHELLE & MARY \\
\hline \multirow[t]{5}{*}{$\begin{array}{l}\text { Heavy Episodic Drinking (HED), days/week } \\
\text { (higher scores = more drinking) }\end{array}$} & Pre-baseline & 2.17 & 5 & 1.25 \\
\hline & Baseline & 0 & 0.75 & 1.33 \\
\hline & Early therapy & 0 & 0.8 & 1.5 \\
\hline & Late therapy & 0 & 0.6 & 0.8 \\
\hline & Follow-up & 0 & 1 & 0.25 \\
\hline \multirow[t]{5}{*}{$\begin{array}{l}\text { Consumption (CONS), days/week } \\
\text { (higher scores = more drinking) }\end{array}$} & Pre-baseline & 2.17 & 5 & 6.25 \\
\hline & Baseline & 0 & 5 & 6.25 \\
\hline & Early therapy & 1 & 0.8 & 5 \\
\hline & Late therapy & 0.8 & 1 & 4.2 \\
\hline & Follow-up & 2.8 & 2.25 & 5.5 \\
\hline \multirow[t]{5}{*}{$\begin{array}{c}\text { Penn Alcohol Craving Scale (PACS), } \\
\text { (higher score = more craving) }\end{array}$} & Inclusion & 11 & 16 & 24 \\
\hline & Baseline & 11.5 & 9.83 & 24.1 \\
\hline & Early therapy & 7.4 & 8 & 21.2 \\
\hline & Late therapy & 5.2 & 7.4 & 19.5 \\
\hline & Follow-up & 3.75 & 11.25 & 20.5 \\
\hline \multirow[t]{2}{*}{$\begin{array}{c}\text { Affect Phobia Test (APT), (higher scores=less } \\
\text { affect phobia; } \geq 72 \text { constitutes adaptive affective } \\
\text { capacity) }\end{array}$} & Inclusion & 52 & 57 & 60 \\
\hline & Follow-up & 78 & 51 & 70 \\
\hline \multirow[t]{2}{*}{$\begin{array}{c}\text { Outcome Questionnaire-45 (OQ-45), } \\
\text { (higher scores = more distress and impairment) }\end{array}$} & Inclusion & 107 & 106 & 66 \\
\hline & Follow-up & 34 & 99 & 54 \\
\hline \multirow[t]{5}{*}{ Initial Psychotherapy Expectations (PEX-1) } & Catharsis & 5.80 & 3.80 & 3.80 \\
\hline & Support & 5.40 & 5.60 & 5.80 \\
\hline & External & 5.60 & 3.80 & 5.80 \\
\hline & Internal & 6.00 & 5.40 & 5.60 \\
\hline & Defensiveness & 1.00 & 1.00 & 1.40 \\
\hline \multirow[t]{5}{*}{ Follow-Up Experiences of Therapy (PEX-2) } & Catharsis & 6.00 & 5.60 & 3.80 \\
\hline & Support & 6.00 & 6.00 & 5.20 \\
\hline & External & 6.00 & 3.00 & 3.00 \\
\hline & Internal & 5.80 & 5.40 & 5.20 \\
\hline & Defensiveness & 1.00 & 1.00 & 2.00 \\
\hline \multirow[t]{2}{*}{$\begin{array}{c}\text { Blood Test } \\
\text { (carbohydrate-deficient transferrin; CDT) } \\
\text { (higher scores = more alcohol consumption; } \\
>2 \text { is considered an elevated value) }\end{array}$} & Inclusion & 1.60 & 3.00 & 1.10 \\
\hline & Follow-up & .90 & & .80 \\
\hline
\end{tabular}


Affect Phobia Therapy for Alcohol Dependence: The Cases of "Carey," "Michelle," and "Mary"

M. Frankl, P. Wennberg, L. Berggraf, \& B. Philips

Pragmatic Case Studies in Psychotherapy, http://pcsp.libraries.rutgers.edu

Volume 15, Module 3, Article 1, pp. 214-257, 01-09-20 [copyright by authors]

Figure 1. Trajectories of Change for the Three Patients on Heavy Episodic Drinking (HED), Consumption (CON), and the Penn Alcohol Craving Scale (PACS)

\section{Carey, pat. 1}
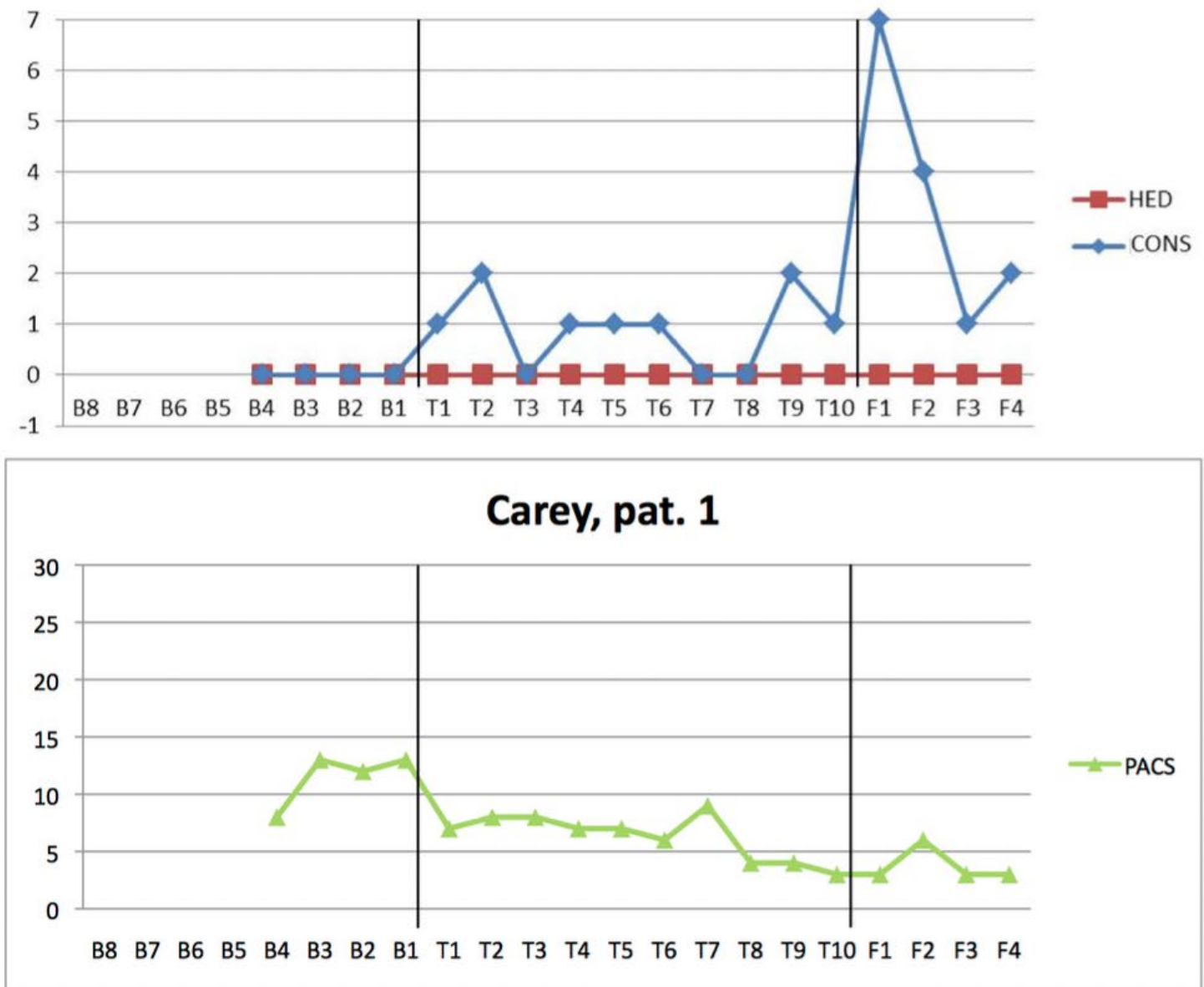

Michelle, pat. 2

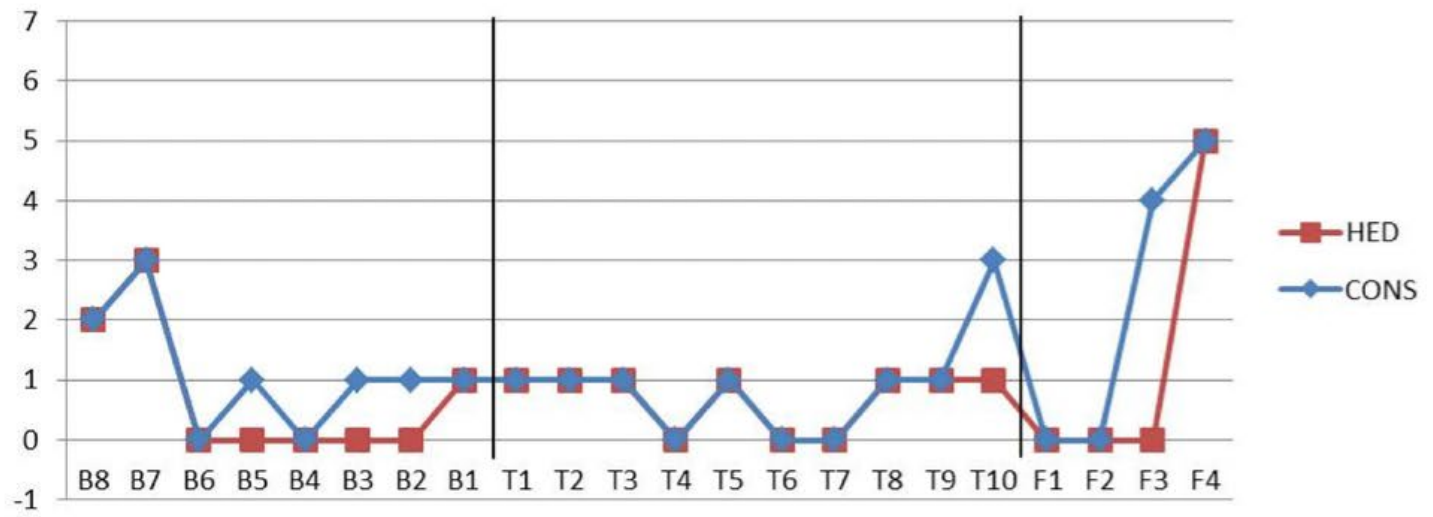


Affect Phobia Therapy for Alcohol Dependence: The Cases of "Carey," "Michelle," and "Mary" M. Frankl, P. Wennberg, L. Berggraf, \& B. Philips

Pragmatic Case Studies in Psychotherapy, http://pcsp.libraries.rutgers.edu

Volume 15, Module 3, Article 1, pp. 214-257, 01-09-20 [copyright by authors]

Figure 1. Trajectories of Change for the Three Patients on Heavy Episodic Drinking (HED), Consumption (CON), and the Penn Alcohol Craving Scale (PACS), page 2

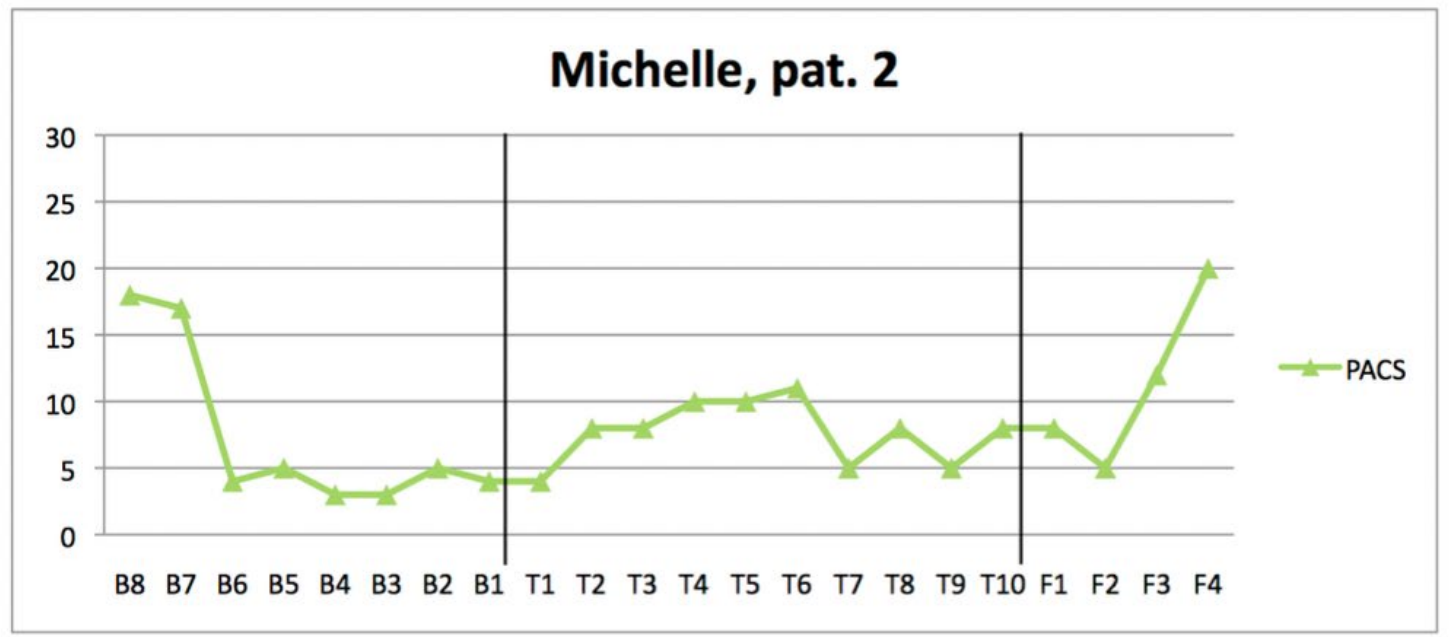

Mary, pat. 3
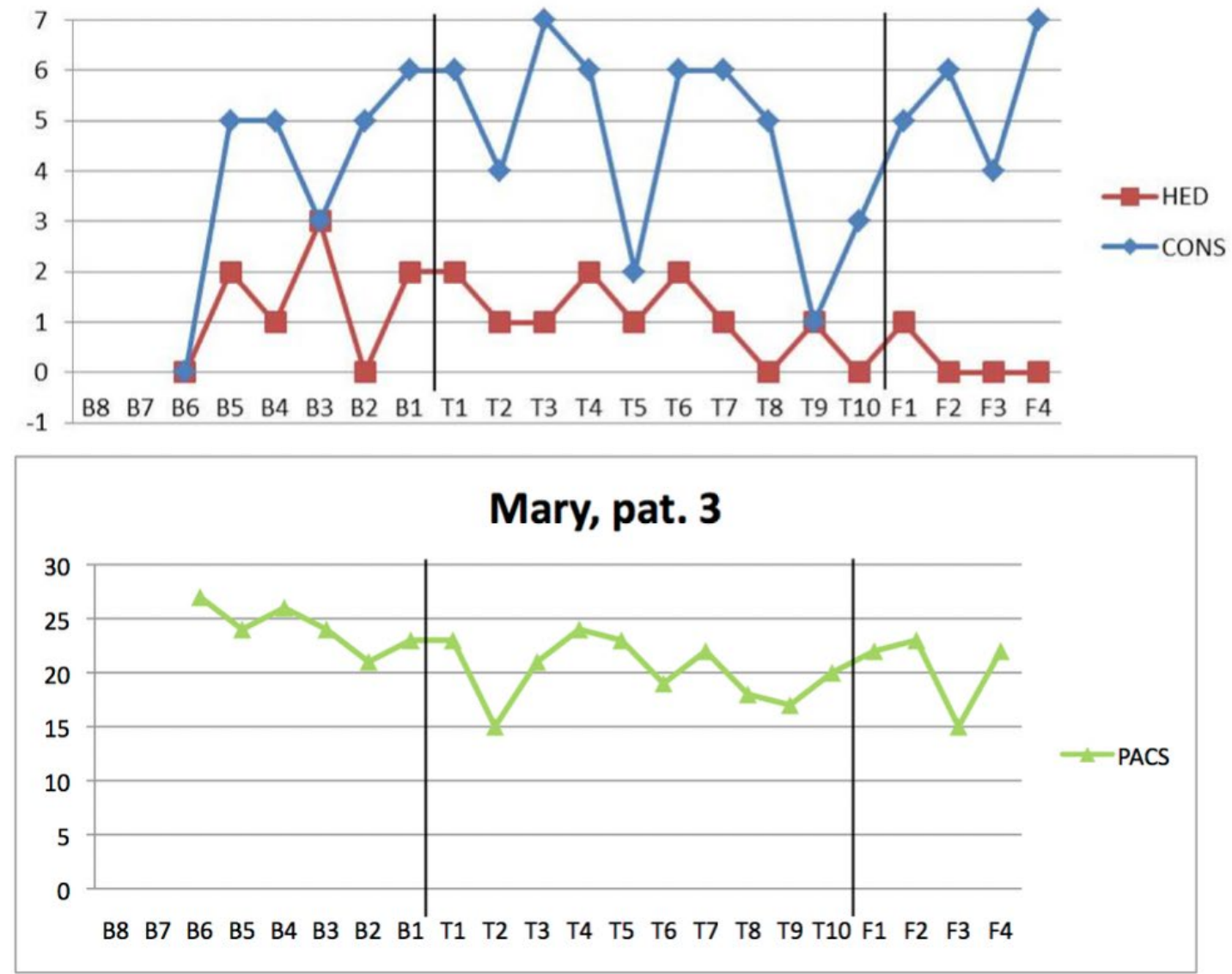